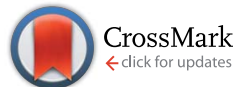

Cite this: RSC Adv., 2016, 6, 98267

\title{
Recent advancements in chemical looping water splitting for the production of hydrogen
}

\author{
G. Voitic* and V. Hacker
}

Chemical looping water splitting or chemical looping hydrogen is a very promising technology for the production of hydrogen. In recent years extensive research has enabled remarkable leaps towards a successful integration of the chemical looping technology into a future hydrogen infrastructure. Progress has been reported with iron based oxygen carriers for stable hydrogen production capacity over consecutive cycles without significant signs of degradation. The high stability improvements were achieved by adding alien metal oxides or by integrating the active component into a mineral structure which offers excellent resistance towards thermal stress. Prototype systems from small $\mu$-systems up to $50 \mathrm{~kW}$ have been operated with promising results. The chemical looping water splitting process was broadened in terms of its application area and utilization of feedstocks using a variety of renewable and fossil resources. The three-reactor system was clearly advantageous due to its flexibility, heat integration capabilities and possibility to produce separate pure streams of hydrogen, $\mathrm{CO}_{2}$ and $\mathrm{N}_{2}$. However tworeactor and single fixed-bed reactor systems were successfully operated as well. This review aims to survey the recently presented literature in detail and systematically summarize the gathered data.

Received 23rd August 2016 Accepted 29th September 2016

DOI: 10.1039/c6ra21180a

www.rsc.org/advances are consumed, leading to the emission of huge quantities of $\mathrm{CO}_{2} \cdot{ }^{1}$ There is a strong consensus in the scientific community that these anthropogenic carbon emissions are jointly responsible for the global temperature rise. ${ }^{2}$ To counteract the trend of continuing temperature increase, clear targets have been presented to the public and to political leaders. One very important task is the reduction of $\mathrm{CO}_{2}$ emissions from fossil fuels by switching to clean and renewable energy sources, to limit the

Graz University of Technology, Institute of Chemical Engineering and Environmental voitic@tugraz.at; viktor.hacker@tugraz.at

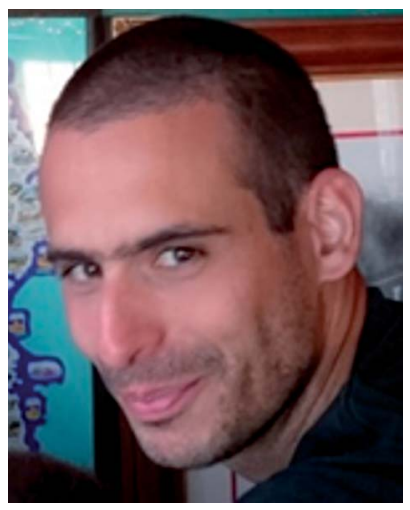

Gernot Voitic is a PhD student at the Institute of Chemical Engineering and Environmental Technology at Graz University of Technology under supervision of Professor Viktor Hacker. He graduated in Chemistry in 2011 on polymer membranes for hydrogen purification. His research interests are hydrogen production, chemical looping technology and catalytic and non-catalytic gas reactions.

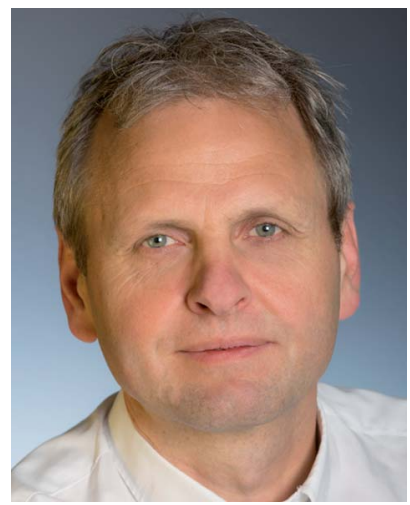

Viktor Hacker received the MSc in mechanical engineering, the $\mathrm{PhD}$ in electrotechnical engineering and 2004 the venia docendi in the field of electrochemical energy technologies from Graz University of Technology. As Associate Professor he is Head of the Fuel Cell Research Group and Deputy Head of the Institute of Chemical Engineering at Graz University of Technology, has long-time experience in the coordination and realization of national and international research projects in the field of fuel cells and hydrogen production and acts as Austrian Representative in the International Energy Agency (IEA), Implementing Agreement on Advanced Fuel Cells. Prof. Hacker published more than hundred papers on fuel cells and hydrogen production. 
average global temperature increase to $2{ }^{\circ} \mathrm{C} .{ }^{3,4}$ In this context hydrogen is considered as a promising clean fuel for future generations. However, hydrogen is a secondary energy source, meaning that its environmental impact is defined by the resources and their production and purification processes. Currently hydrogen is mainly produced in large scale reforming plants with fossil hydrocarbons or coal as feed, which results in significant $\mathrm{CO}_{2}$ emissions. ${ }^{5}$ There are two main technological routes, which enable the production of clean hydrogen. The first option is the application of technologies which utilize $\mathrm{CO}_{2}$ neutral resources or energy for instance electrolysis from wind and solar or reforming of renewable hydrocarbons. ${ }^{6}$ The second option is production based on fossil fuels in combination with carbon capture and storage systems. ${ }^{7}$ Both pathways are pursued using several different technologies, which are already in operation as prototypes or on an industrial scale. However, they usually suffer from higher hydrogen production costs compared to conventional plants, which hinders market penetration. ${ }^{\mathbf{6} 8}$ Chemical looping hydrogen systems represent a promising technology that can offer both the use of renewable, $\mathrm{CO}_{2}$ neutral resources as well as efficient $\mathrm{CO}_{2}$ sequestration capabilities. ${ }^{7}$ Historically, the chemical looping process for the generation of hydrogen was introduced as the "steam-iron" process in 1903 by Howard Lane and his co-workers. ${ }^{9-17}$ Nowadays, it is still referred to as a steam-iron process, although it is usually described as a modification of the chemical looping combustion process CLC and is thus named "chemical looping hydrogen" CLH or "chemical looping water splitting" CLWS. Generally, chemical looping technology (Fig. 1) uses a solid oxygen carrier, which supplies oxygen for the combustion of a fuel and reduction of the solid material (eqn (1)). This omits the utilization of air as oxygen supply and thus enables the fuel conversion to a pure stream of $\mathrm{CO}_{2}$ and $\mathrm{H}_{2} \mathrm{O}$, which can be easily separated by condensation. The solid material is reoxidized with air to regenerate the depleted oxygen (eqn (2)). The addition of a third reaction step enables the production of pure hydrogen by re-oxidizing the oxygen carrier with water (eqn (3)). An air oxidation might still be executed to close the looping cycle, but it reduces the hydrogen production rate and thereby the maximum efficiency of an integrated system as discussed by Hacker et al. in relation to different fuels. ${ }^{18,19}$

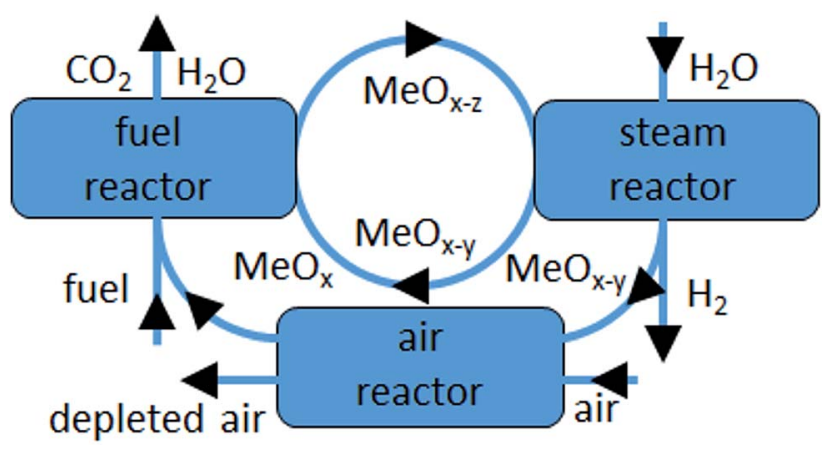

Fig. 1 Process schematic of the chemical looping hydrogen production process with an alternative air oxidation.

$$
\begin{gathered}
\mathrm{C}_{n} \mathrm{H}_{2 m}+(2 n+m) \mathrm{Me}_{x} \mathrm{O}_{y} \rightarrow \\
m \mathrm{H}_{2} \mathrm{O}+n \mathrm{CO}_{2}+(2 n+m) \mathrm{Me}_{x} \mathrm{O}_{y-1} \\
\mathrm{Me}_{x} \mathrm{O}_{y-1}+0.5 \mathrm{O}_{2} \rightarrow \mathrm{Me}_{x} \mathrm{O}_{y} \\
\mathrm{Me}_{x} \mathrm{O}_{y-1}+\mathrm{H}_{2} \mathrm{O} \rightarrow \mathrm{H}_{2}+\mathrm{Me}_{x} \mathrm{O}_{y}
\end{gathered}
$$

This state-of-the-art review focuses on very recent research data presented in literature on the subject of hydrogen production by means of chemical looping technology. The publications studied were divided between the main sections (i) oxygen carrier development, (ii) reactor design, (iii) process development, (iv) process simulation and (v) kinetic studies. An overview of the evaluated data is presented in tables for each section.

\section{Oxygen carrier development}

The oxygen carrier functions as a transport intermediate to deliver pure oxygen without nitrogen dilution from the oxidizing stream, air or water, to the fuel. The utilization of a suitable oxygen carrier is of great importance in chemical looping systems for hydrogen production. Thus, a great deal of literature deals with improvements mainly implemented by means of two different approaches, (i) optimizing the composition or (ii) optimizing the particle structure. A summary of the utilised oxygen carrier is presented in Table 1 . Key properties for industrial applications, which must be met by suitable oxygen carriers are: $:^{20-30}$

- A high oxygen exchange capacity.

- Favourable thermodynamics and reactivity regarding the selected fuel for the reduction reactions.

- A low risk of carbon formation.

- Structural stability under continuous reduction and oxidation cycles.

- High reactivity in the oxidation reactions.

- Good fluidization properties and resistance to attrition, which is important in fluidized reactor systems.

- Feasible material and production costs.

- Environmental friendly characteristics.

Various metals viz. Fe, W, Sn, Ni, Cu, Mn and Ce have been tested as the main active component. However, the more recent work almost exclusively investigated iron based oxygen carrier. ${ }^{31}$ As pure metals do not fulfil the listed requirements, inert components such as $\mathrm{ZrO}_{2}, \mathrm{TiO}_{2} \mathrm{SiO}_{2} \mathrm{Al}_{2} \mathrm{O}_{3}$ as additives are used to improve the mechanical and chemical properties. ${ }^{32}$ Additionally, the active component can be incorporated into a mineral structure, for instance a perovskites or a spinel structure, which are known for their mechanical resistance or two active metals are combined as a bimetallic oxygen carrier to generate synergetic effects of their components. ${ }^{33}$

\section{Zirconia as additive}

Liu et al..$^{34}$ achieved a stable hydrogen yield of $90 \%$ based on the theoretical value over 20 cycles by adding up to $30 \mathrm{wt} \%$ of $\mathrm{ZrO}_{2}$. The structural analysis revealed partial sintering of iron 


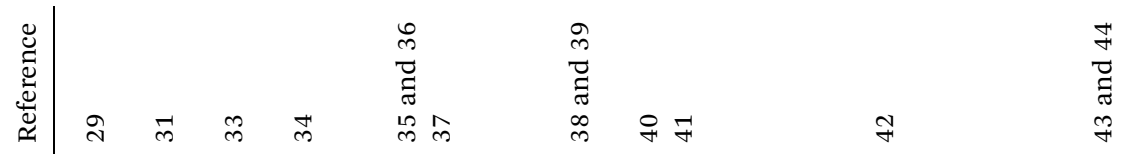




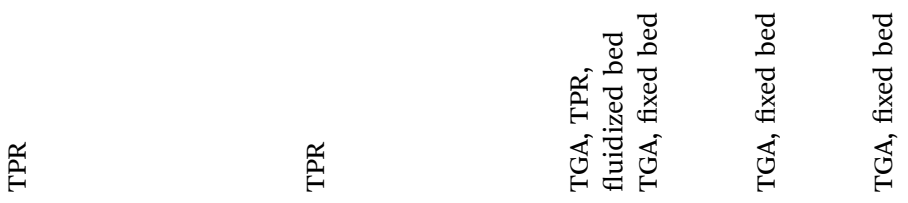




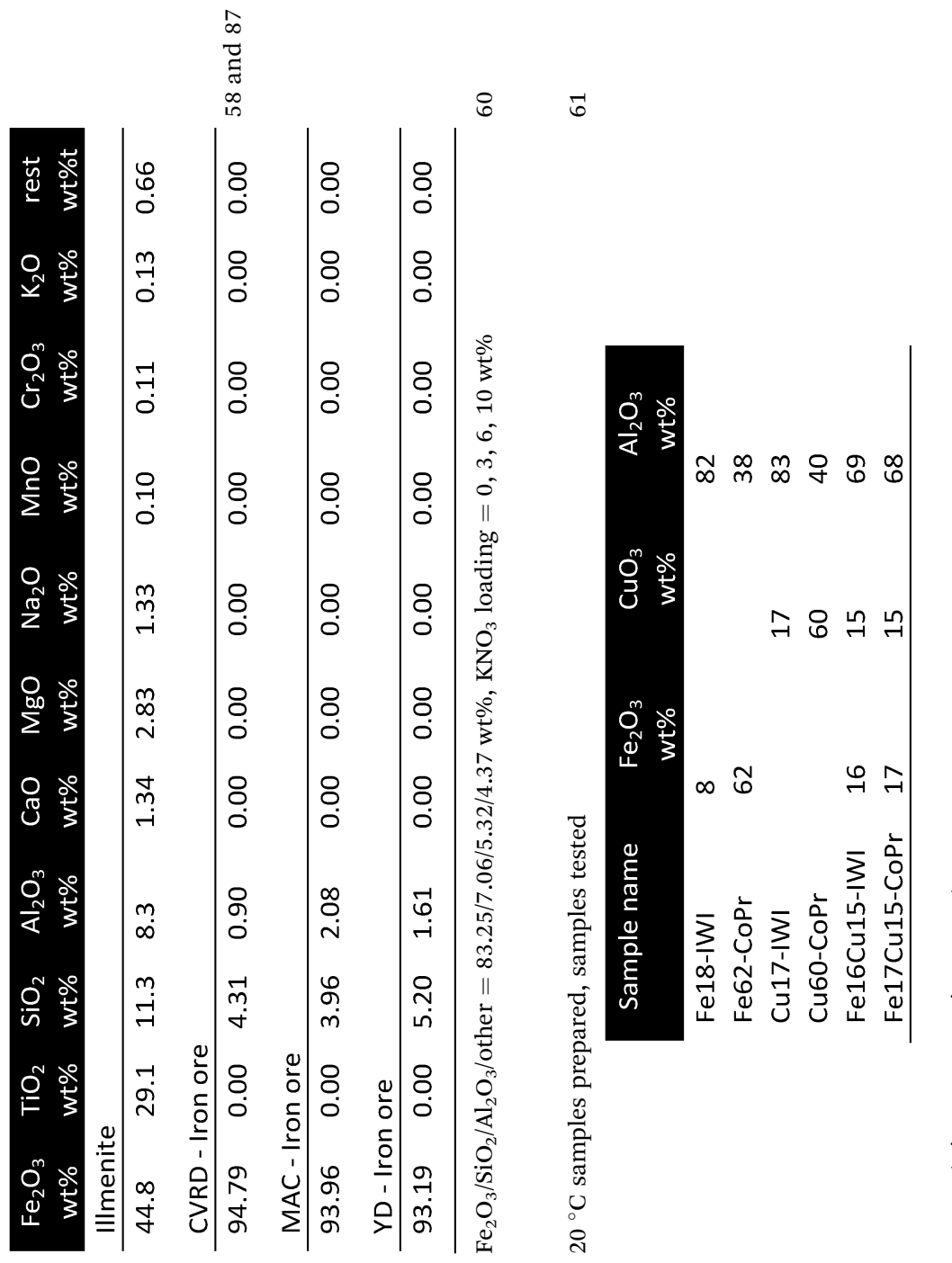

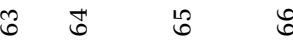

6

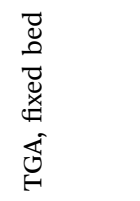

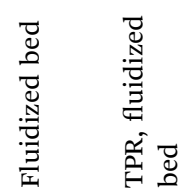

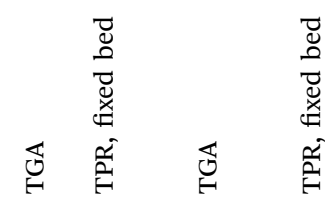

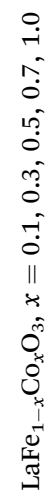
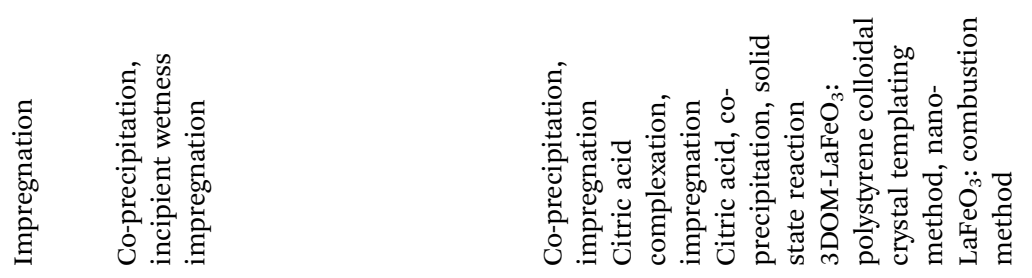

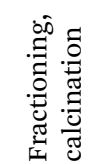

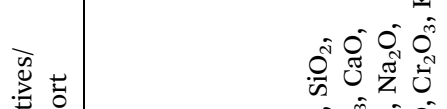

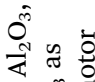

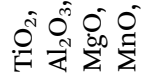

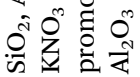

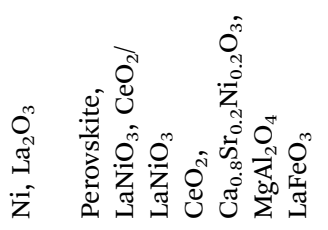

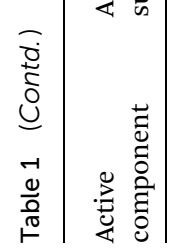

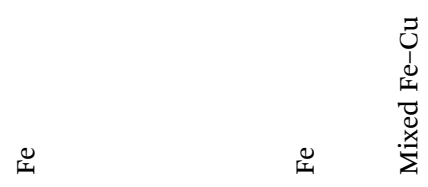



$\sqrt{\pi} \frac{\pi}{\pi}$

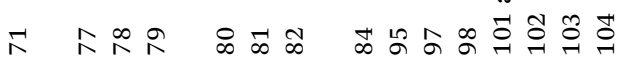

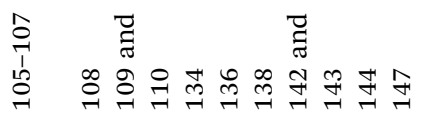

$\overline{\mathrm{a}}$ 
particles but the pore structure was maintained and no chemical interaction between the active redox component and the support, which leads to the unreactive component $\mathrm{Fe}-\mathrm{Zr}-\mathrm{O}$, was observed. Cho et al. ${ }^{35}$ analysed the structural changes of an oxygen carrier with a $20 \mathrm{wt} \%$ loading of $\mathrm{Fe}_{2} \mathrm{O}_{3}$ on $\mathrm{ZrO}_{2}$ at $750{ }^{\circ} \mathrm{C}$. After 10 redox cycles the iron particles were homogenously distributed with only slight signs of sintering as long as a deep reduction was avoided and reduction was stopped at wustite. However, after deep reductions to Fe, diffusion of iron particles to the outer regions and significant growth of iron grains were found. Therefore, samples reduced to wustite performed better in terms of hydrogen yield. The oxygen carriers were successfully applied in a fixed bed reactor at $800{ }^{\circ} \mathrm{C}$ using methane as the reducing feed..$^{36}$ The redox reaction results were used to determine the design guideline for a $1 \mathrm{MW}_{\text {th }}$ chemical looping plant with a bed inventory of $170-220 \mathrm{~kg} \mathrm{MW} \mathrm{th}^{-1}$. The stability was further enhanced by using an yttrium-stabilized zirconia (YSZ) defect support, which provides strong support and inhibits iron sintering. ${ }^{35}$ The iron diffusion, which leads to uneven distribution of active metal and support, can be avoided by preventing particle sintering. It was found that the stability was increased by an activation process consisting of 10 cycles of reduction including air-oxidations. The formation of large cracks and pores occurred, which directed the iron diffusion towards the newly formed cavities. Thus, a heterogeneous particle distribution was maintained. Samples, which underwent an activation method, provided higher reduction rates using methane as feed compared to reference samples without the prior treatment. Kosaka et al. ${ }^{37}$ reported similar improvements of redox behaviour with iron oxide supported by yttriumstabilized zirconia (YSZ) compared to $\mathrm{Fe}_{2} \mathrm{O}_{3} / \mathrm{ZrO}_{2}$ reference samples. A positive correlation between the reduction rate constant and the oxide ion conductivity of YSZ due to Y-doping was observed in the reduction step and the oxidation reaction. Improved reaction rates compared to $\mathrm{ZrO}_{2}$ were reported, when using samples with $\mathrm{CeO}_{2}$ and $\mathrm{Ce}_{0.8} \mathrm{Gd}_{0.2} \mathrm{O}_{2-\delta}$ (GDC) support. In contrast to the enhanced ion conductive of $\mathrm{YSZ} \mathrm{CeO}_{2}$ and GDC increase the electronic conductive and accelerate the reduction kinetics of FeO to Fe significantly (Fig. 2). ${ }^{33}$ This suggests that oxygen vacancy formation by cerium plays an important role in the acceleration of the redox reaction.

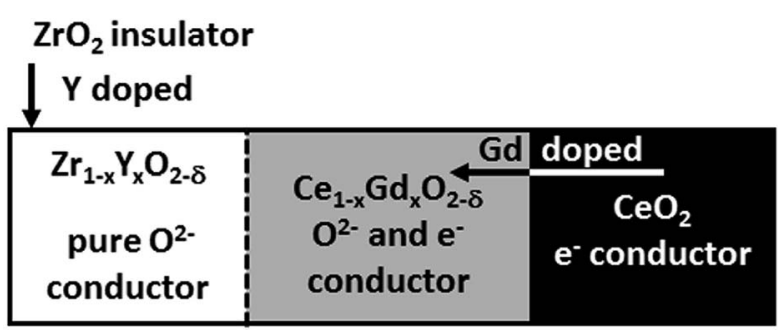

Fig. 2 Physical properties of the support materials utilized by Kosaka et al. ${ }^{37}$ Reprinted and adapted from F. Kosaka, H. Hatano, Y. Oshima, and J. Otomo, Iron oxide redox reaction with oxide ion conducting supports for hydrogen production and storage systems, Chem. Eng. Sci., 2015, 123, 380-387, Copyright (2014), with permission from Elsevier.
The GDC support, which contained both attributes, the ionand electric conductivity, possessed the highest performance in redox experiments at $550-800{ }^{\circ} \mathrm{C}$ with hydrogen as reducing feed followed by a steam oxidation.

\section{$\mathrm{CeO}_{2}$ as active component}

The stabilizing effects of a $\mathrm{ZrO}_{2}$ support with $\mathrm{CeO}_{2}$ was investigated by Zheng et al. ${ }^{38}$ Samples with a metal ratio of $\mathrm{Ce} / \mathrm{Zr}=8$ / 2 and with pore sizes ranging from 100-200 $\mathrm{nm}$ were prepared using the colloidal crystal method. The pore sizes were controlled by the sizes of the PMMA template spheres. A nonporous sample prepared by co-precipitation was used as a reference sample. $\mathrm{H}_{2}$-TPR measurements revealed a single reduction peak (at around $650{ }^{\circ} \mathrm{C}$ ) for the macro-porous samples, whereas the nonporous oxygen carrier showed two separated reduction peaks, which can be related firstly to the exchange of bulk oxygen $\left(600{ }^{\circ} \mathrm{C}\right)$ and secondly to the lattice oxygen $\left(900{ }^{\circ} \mathrm{C}\right)$. The merging of the two reduction peaks suggested an improved mobility of lattice oxygen in the macro porous samples, which enhanced its reducibility. Cyclic experiments were performed in a fixed bed quartz reactor at $800{ }^{\circ} \mathrm{C}$ using methane as reducing agent. The macro porous samples indicated an average methane conversion ranging from $46-50 \%$ and $\mathrm{a}_{2} / \mathrm{CO}$ ratio approaching the stoichiometric value. The hydrogen consumption increased with declining pore sizes. The methane conversion of the nonporous sample was $4 \%$-points lower with a $\mathrm{H}_{2} / \mathrm{CO}$ ratio of two, which suggested methane cracking induced by a deficiency of oxygen, and thus an increased risk of carbon formation. A similar trend was observed in steam oxidations. A declining pore size raised the hydrogen production rate and the amount of hydrogen. Stability measurements over 10 cycles revealed a clearly visible continuous decrease of produced hydrogen. SEM images showed that the three-dimensionally ordered macro-porous structure had collapsed, however the samples maintained a sufficient porosity. The influence of different calcination temperatures on redox performance and structural traits of the proposed macroporous $\mathrm{CeO}_{2}-\mathrm{ZrO}_{2}$ oxygen carrier samples were studied. ${ }^{39}$ Increasing calcination temperatures from 450 to $850{ }^{\circ} \mathrm{C}$ changed the structure due to the growth of larger grains. Lower calcination temperatures resulted in higher structured samples (Fig. 3), which yielded better $\mathrm{CH}_{4}$ conversions and $\mathrm{H}_{2} / \mathrm{CO}$ ratios. A similar trend for the steam oxidation was observed, a decreasing hydrogen production rate with increasing calcination temperature. The results suggest that the structural properties of $\mathrm{CeZrO}_{2}$ strongly influenced the mobility of lattice oxygen, thus effecting conversion efficiency during the redox reactions. All samples revealed a loss of produced amount of hydrogen after 10 consecutive cycles. However, a high calcination temperature led to a complete loss of the initial macrostructure but preserved the microscale porosity (Fig. 3). Lower calcination temperatures stabilized the three dimensional structures, even if the samples were used at high reaction temperatures. Nevertheless, stability experiments indicated a gradual loss of the skeletal structure, which left the long term cycle stability disputable. 


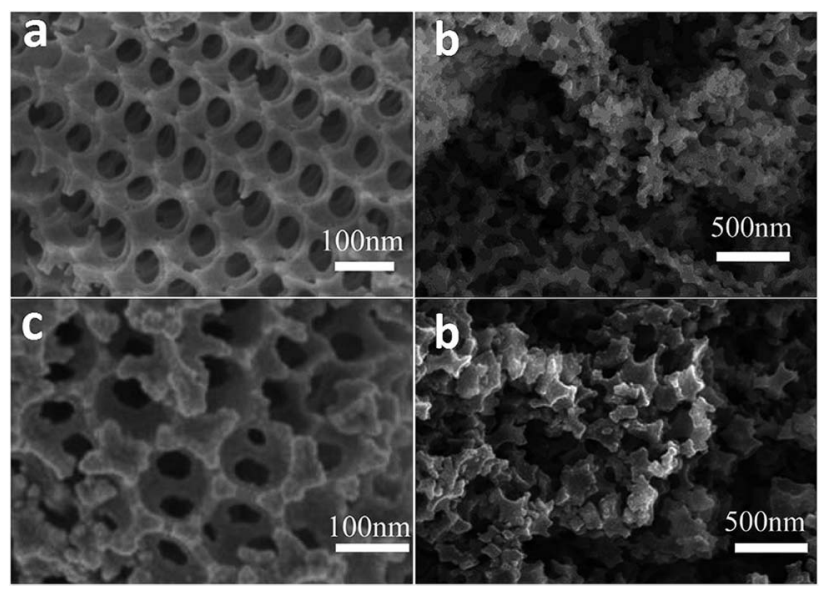

Fig. 3 SEM images of $\mathrm{CeO}_{2} / \mathrm{ZrO}_{2}$ oxygen carriers. Fresh samples after a calcination step at different temperatures (a) $450{ }^{\circ} \mathrm{C}$, (c) $750^{\circ} \mathrm{C}$. After 10 redox cycles, the influence of different calcination temperatures (b) $450{ }^{\circ} \mathrm{C}$, (d) $750{ }^{\circ} \mathrm{C}$ on the structural changes can be observed. ${ }^{39}$ Reprinted and adapted from Y. Zheng, Y. Wei, K. Li, X. Zhu, H. Wang, and $Y$. Wang, Chemical-looping steam methane reforming over macroporous $\mathrm{CeO}_{2}-\mathrm{ZrO}_{2}$ solid solution: effect of calcination temperature, Int. J. Hydrogen Energy, 2014, 39, 13361-13368, Copyright (2014), with permission from Elsevier.

\section{$\mathrm{CeO}_{2}$ as additive}

Synergetic effects of a mixture of $\mathrm{CeO}_{2}$ and $\mathrm{Fe}_{2} \mathrm{O}_{3}$ were investigated by $\mathrm{Zhu}$ et al. ${ }^{31,40} \mathrm{CeO}_{2}$ was used as support material with iron oxide dispersed on the surface. $\mathrm{Fe}^{3+}$ was partially imbedded in the $\mathrm{CeO}_{2}$ lattice structure, thus changing the chemical properties of the particles. An enhanced reducibility of the mixed Ce-Fe oxide was observed in $\mathrm{H}_{2}$-TPR measurements and CL-SMR at temperatures of $800-900{ }^{\circ} \mathrm{C}$ with a higher lattice oxygen mobility compared to single oxides. An increasing iron content raised the amount of released hydrogen in the oxidation step due to the high oxygen intake capability. The sample with the molar ratio of $\mathrm{Ce} / \mathrm{Fe}=1$ was selected for 10 consecutive cycles with fixed reduction and oxidation reaction times at $850{ }^{\circ} \mathrm{C}$. A steady decrease of the $\mathrm{CH}_{4}$ conversion from roughly $63 \%$ to $55 \%$ was observed, while the amount of produced syngas and the $\mathrm{H}_{2} / \mathrm{CO}$ ratio remained unchanged. The oxidations showed only a slight decline in the produced hydrogen with no carbonaceous impurities. During the methane reduction step, the formation of $\mathrm{CeFeO}_{3}$ occurred by means of a solid-solid reaction, which was re-oxidized to $\mathrm{CeO}_{2}$ and $\mathrm{Fe}_{3} \mathrm{O}_{4}$ during the steam oxidation step. However, a $\mathrm{Ce}-\mathrm{Fe}-\mathrm{O}$ phase equilibrium was preserved with constant composition during the redox process, thus increasing the oxygen mobility by the formation of abundant oxygen vacancies. Gu et al. ${ }^{41}$ reported a significant improved reducibility of surface and bulk oxygen in iron oxide supported with $\mathrm{CeO}_{2}$ prepared using the coprecipitation method. Samples produced by mechanical mixing exhibited only a slightly better performance. Thus the formation of a solid solution of $\mathrm{CeFeO}_{3}$ and the structural change, which were strongly related to the synthesis method, were key to enhancing the redox performance. The increasing Ce content increased its specific surface which reached a maximum at the composition of $\mathrm{Fe} / \mathrm{Ce}=80 / 20$ and decreased afterwards. Small Ce-particles with a high dispersity and strong chemical interaction were formed and stabilized the structure after several redox cycles. The improved stability of iron oxide particles by adding Ce was also reported by Romero et al. ${ }^{42}$ Small amounts of $\mathrm{CeO}_{2}$ were added to iron oxide supported on $\mathrm{Al}_{2} \mathrm{O}_{3}$ with the final composition of $\mathrm{Fe}_{2} \mathrm{O}_{3} / \mathrm{Al}_{2} \mathrm{O}_{3} / \mathrm{CeO}_{2}$ 98/1.75/ $0.25 \%$. The sample did not suffer from any deactivation during 17 cycles at $500{ }^{\circ} \mathrm{C}$ when fully oxidized, but the cycle time slightly increased.

\section{$\mathrm{MoO}_{3}$ as additive}

When replacing $\mathrm{CeO}_{2}$ with $\mathrm{MoO}_{3}$ with a content of $0.25 \%$, a better steam oxidation behaviour was observed, however a reduced cycle stability, especially within the first 8 cycles led, to a decreasing amount of produced hydrogen. ${ }^{42}$ The combined addition of $\mathrm{CeO}_{2}$ and $\mathrm{MoO}_{3}$ did not improve either the redox behaviour or stability. Datta et al. ${ }^{43,44}$ impregnated iron oxide samples supported on $20 \mathrm{wt} \% \mathrm{Ce}_{0.5} \mathrm{Zr}_{0.5} \mathrm{O}_{2}$ with different molybdenum concentrations to achieve a final Mo loading of 0.96-5.5 wt\%. The formation of a spinel-type ferrite $\mathrm{Mo}_{x} \mathrm{Fe}_{3-x} \mathrm{O}_{4}$ was reported, which inhibited the contact between the iron particles and impeded the deep reduction from $\mathrm{FeO}$ to Fe. This hindered sintering and deactivation of the active component. The increasing Mo content led to a higher temperature for the reduction with hydrogen and a higher air-oxidation temperature. However, decreasing reduction activation energy with increasing molybdenum content was observed. A significant improvement in stability was reported for Mo-impregnated samples compared to a reference $\mathrm{Fe}_{2} \mathrm{O}_{3}-\mathrm{Ce}_{0.5} \mathrm{Zr}_{0.5} \mathrm{O}_{2}$ sample. A Mo content of $\geq 1.5 \mathrm{wt} \%$ preserved a hydrogen production amount of at least $90 \%$ from the theoretical value after 100 cycles at $7500^{\circ} \mathrm{C}$. A further extended stability test with 200 cycles revealed a loss of $10 \%$ from the initial amount of produced hydrogen within the first 40 cycles followed by a stable production afterwards. The trade-off for higher stability was the amount of produced hydrogen per cycle, which was only $30-$ $34 \%$ of the amount theoretically possible. Wang et al. ${ }^{45}$ reported a decrease in the activation energy by adding small amounts of Mo $<10 \mathrm{~mol} \%$. TPR experiments revealed a shift of the reduction peak of iron towards lower temperatures from $610{ }^{\circ} \mathrm{C}$ to $572{ }^{\circ} \mathrm{C}$. A third broad peak at $758{ }^{\circ} \mathrm{C}$ was visible, which was related to the reduction of $\mathrm{Mo}^{\circ}$ and to the formation of $\mathrm{Fe}_{2} \mathrm{Mo}_{3} \mathrm{O}_{8}$. An increased production rate and higher amount of hydrogen during steam oxidation were measured. A shift to lower oxidation temperatures was observed from $400{ }^{\circ} \mathrm{C}$ to $350{ }^{\circ} \mathrm{C}$, with the sample consisting of $8 \mathrm{~mol} \%$ Mo revealing the best performance.

\section{$\mathrm{CaO}$ as additive}

Improved stability of iron based oxygen carriers by the combination with $\mathrm{CaO}$ was investigated by some work groups. ${ }^{46-48}$ Datta $^{46}$ added $2.5 \mathrm{wt} \% \mathrm{CaO}$ to $\mathrm{Fe}_{2} \mathrm{O}_{3}$ samples supported with either $\mathrm{SiO}_{2}(7.5 \mathrm{wt} \%)$ or $\mathrm{Al}_{2} \mathrm{O}_{3}(5 \mathrm{wt} \%)$. The combination of $\mathrm{SiO}_{2}$ and $\mathrm{CaO}$ enabled a stable hydrogen yield of $95 \%$ of its initial value over 100 cycles as long as the reaction temperature 
remained below $750{ }^{\circ} \mathrm{C}$. A significant stability loss was observed at higher temperatures caused by the agglomeration of $\mathrm{SiO}_{2}$. The sample with $\mathrm{Al}_{2} \mathrm{O}_{3}$ and $\mathrm{CaO}$ stabilized the oxygen carrier to a hydrogen amount of $70-80 \%$ of its initial value after 100 cycles. Datta suggested that the formation of $\mathrm{CaO}$ formed a dispersed ferrite structure, which inhibited sintering. Ismail et al. ${ }^{47}$ prepared mixtures of $\mathrm{Fe}_{2} \mathrm{O}_{3}$ with $50,57.3$ and $66.7 \mathrm{~mol} \%$ of $\mathrm{CaO}$. After calcination $\mathrm{CaO}, \mathrm{CaFe}_{2} \mathrm{O}_{4}, \mathrm{Ca}_{2} \mathrm{Fe}_{2} \mathrm{O}_{5}, \mathrm{CaO}$ and $\mathrm{Fe}_{2} \mathrm{O}_{3}$ were identified in the different samples depending on the mol\% of CaO. Deviations from the expected equilibrium compositions were detected as a result of inhomogeneous mixing and slow solid-state diffusion during the calcination process. The calcium ferrite samples were successfully reduced with $\mathrm{CO}$ and $\mathrm{H}_{2}$, forming the stable component $\mathrm{Ca}_{2} \mathrm{Fe}_{2} \mathrm{O}_{5}$, and efficiently re-oxidized with $\mathrm{CO}_{2}$. Equilibrium partial pressure values suggest that the oxidation of $\mathrm{Ca}_{2} \mathrm{Fe}_{2} \mathrm{O}_{5}$ enables a higher steam conversion to hydrogen compared to the unmodified iron to wustite oxidation. The mixed metal ferrites achieved a stable gas conversion during consecutive redox reactions over 20 cycles, whereas the pure iron sample, which started with a high amount of exchanged-oxygen/sample-mass, indicated a loss of approximately $90 \%$ within 10 cycles. Deep reduction experiments resulted in the formation of segregated phases of Fe and $\mathrm{CaO}$, hence a significant degradation of the cycle stability. Fluidized redox experiments indicated high attrition losses of the calcium ferrite samples of $4-6 \%$ wt. Thus, the mechanical strength needs to be improved for industrial applications. Chan et $a l .{ }^{48}$ observed high steam conversion efficiencies with an equilibrium composition of $75 / 25 \mathrm{~mol} \% \mathrm{H}_{2} / \mathrm{H}_{2} \mathrm{O}$ in a single oxidation step using a $\mathrm{Ca}_{2} \mathrm{Fe}_{2} \mathrm{O}_{5}$ sample. A complete recovery to the initial stage of $\mathrm{Ca}_{2} \mathrm{Fe}_{2} \mathrm{O}_{5}$ was achieved without the requirement of an air oxidation. The amount of released hydrogen was $88.9 \%$ compared to a $\mathrm{Fe}_{2} \mathrm{O}_{3} / \mathrm{ZrO}_{2}$ reference sample. However, $\mathrm{Ca}_{2} \mathrm{Fe}_{2} \mathrm{O}_{5}$ suffered from a slow reduction rate, which was about twice as long as pure iron oxide caused by an unfavourable reduction equilibrium. To overcome the trade-off and utilize the higher steam oxidation efficiency a combination of two oxygen carriers in two reactors was suggested. During reduction the feed initially reduces the $\mathrm{Ca}_{2} \mathrm{Fe}_{2} \mathrm{O}_{5}$ containing bed. The off-gas can still convert a pure iron oxide bed and enables complete conversions to $\mathrm{CO}_{2}$ for efficient carbon sequestration. During oxidation the flow direction changes and passes first through the iron bed and finally through the $\mathrm{CaO}+\mathrm{Fe}$ bed. Thus, the higher steam conversion capabilities are utilized.

\section{$\mathrm{Al}_{2} \mathrm{O}_{3}$ as additive}

It is well known that the addition of $\mathrm{Al}_{2} \mathrm{O}_{3}$ can stabilize the cycle stability of iron based oxygen carriers. However sample studies of deeply reduced iron oxide supported by $\mathrm{Al}_{2} \mathrm{O}_{3}$ have shown that the formation of unreactive hercynite $\mathrm{FeAl}_{2} \mathrm{O}_{4}$ occurred. ${ }^{49-52}$ Liu et al..$^{53}$ investigated possibilities for inhibiting the formation of hercynite and preserving the initial reduction rates by adding $\mathrm{Na}_{2} \mathrm{O}$ and $\mathrm{MgO}$. These additives were expected to prevent the formation of $\mathrm{FeAl}_{2} \mathrm{O}_{4}$ by forming the stable compounds $\mathrm{MgAl}_{2} \mathrm{O}_{4}$ and $\mathrm{NaAlO}_{2}$ instead, which also act as support materials. The two oxides were prepared by precipitation with the

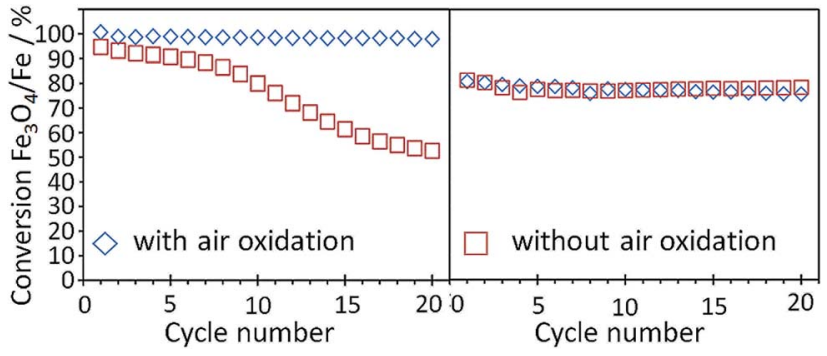

Fig. 4 The conversion degree of $\mathrm{Fe}_{3} \mathrm{O}_{4}$ to $\mathrm{Fe}$ as a function of cycle numbers with $0.3 \mathrm{~g}$ of NAFO (left) and NMAFO (right) in a packed bed reactor at $850{ }^{\circ} \mathrm{C}$ with or without an air oxidation step. ${ }^{53}$ Reproduced from W. Liu, M. Ismail, M. T. Dunstan, W. Hu, Z. Zhang, P. S. Fennell, S. A. Scott, and J. S. Dennis, Inhibiting the interaction between $\mathrm{FeO}$ and $\mathrm{Al}_{2} \mathrm{O}_{3}$ during chemical looping production of hydrogen, RSC Adv., 2015, 5, 1759-1771, Copyright (2015), with permission from the Royal Society of Chemistry.

compounds $\mathrm{Fe}, \mathrm{Al}$ and $\mathrm{Na}(\mathrm{NAFO})$ and $\mathrm{Fe}, \mathrm{Mg}, \mathrm{Al}$ and $\mathrm{Na}$ (NMAFO). When cycled under conditions suitable for producing hydrogen at $1123 \mathrm{~K}$, both oxygen carriers showed stable performance over 20 cycles, demonstrating approximately $100 \%$ and $80 \%$ of their theoretical hydrogen capacities, as long as an air oxidation was included in each step. Cycle experiments without air oxidation revealed a conversion loss of roughly $50 \%$ for NAFO, while the NMAFO sample retained its stability regardless of the oxidation procedure. The gradual formation of $\mathrm{NaFeO}_{2}$ led to free $\mathrm{Al}_{2} \mathrm{O}_{3}$ and the formation of hercynite in consecutive cycles. However, in the presence of $\mathrm{Mg}^{2+}$ cations, $\mathrm{Al}_{2} \mathrm{O}_{3}$ formed the stable compound of $\mathrm{MgAl}_{2} \mathrm{O}_{4}$ thus stabilized the NMAFO sample (Fig. 4).

\section{Natural minerals as oxygen carrier}

The application of oxygen carriers from natural deposits in chemical looping has attracted the attention of several research groups in the past. ${ }^{54-56} \mathrm{Ku}$ et al. ${ }^{57}$ considered the utilization of natural-ilmenite $\left(\mathrm{Fe}_{2} \mathrm{TiO}_{5}\right)$ as an inexpensive and abundant oxygen carrier. In a segmented reduction the sample was gradually reduced to $\mathrm{Fe}_{2} \mathrm{TiO}_{4}$ and $\mathrm{FeTiO}_{3}$ and finally $\mathrm{Fe}$ and $\mathrm{TiO}_{2}$. The consecutive air oxidation led to the formation of a sample containing only $\mathrm{Fe}_{2} \mathrm{O}_{3}$ and $\mathrm{TiO}_{2}$. Hydrogen generation by steam oxidation was feasible at $900{ }^{\circ} \mathrm{C}$ and $\mathrm{Fe}_{3} \mathrm{O}_{4}$ and $\mathrm{FeTiO}_{3}$ were found in the oxidized sample. The stability tests showed no significant changes at $900{ }^{\circ} \mathrm{C}$ after 100 cycles with an oxygen storage capacity of approximately $33 \%$. Sample analysis revealed agglomerated structures of $\mathrm{Fe}_{2} \mathrm{O}_{3}$ but due to the presence of cracks and pores, the reactivity was maintained. Xiao et $a .^{58}$ compared ilmenite with different natural iron ores in a reducing feed using different $\mathrm{CO} / \mathrm{N}_{2}$ ratios. The ilmenite samples had the lowest weight loss during the reduction because of the lower iron oxide content, however a very high resistance to solid carbon and iron carbon formation was observed. Tong et al. ${ }^{59}$ suggested that the introduction of $\mathrm{Fe}_{2} \mathrm{O}_{3}$ in a $\mathrm{TiO}_{2}$ network leads to the formation of lattice substitution and interstitial defects in the support framework. These defects increase the rate of oxygen anion diffusion. In unsupported iron 

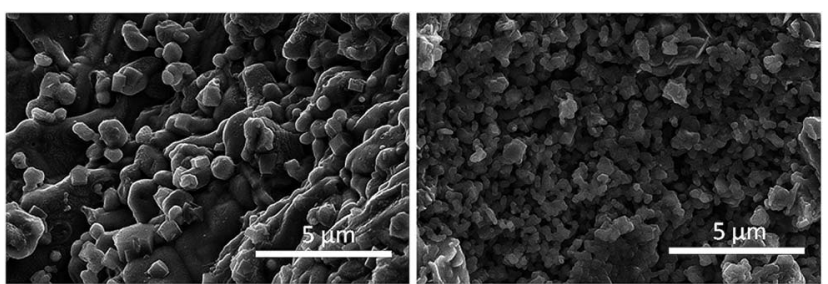

Fig. 5 SEM images of the oxygen carrier after 10 cycles, original iron ore (left) and iron ore loaded with $10 \mathrm{wt} \% \mathrm{KNO}_{3}$ (right). ${ }^{60}$ Reprinted and adapted with permission from W. Liu, L. Shen, H. Gu, and L. Wu, Chemical looping hydrogen generation using potassium-modified iron ore as an oxygen carrier, Energy Fuels, 2016, 30, 1756-1763, Copyright (2016), American Chemical Society.

oxides the outward iron cation diffusion was dominant, whereas in a supported iron oxide, like ilmenite, both the outwards diffusion of iron cations and the inwards diffusion of oxygen anions occurred. Liu et al. ${ }^{60}$ impregnated natural hematite, which consisted of $\mathrm{Fe}_{2} \mathrm{O}_{3}$ supported with $\mathrm{SiO}_{2}$ and $\mathrm{Al}_{2} \mathrm{O}_{3}$, with a solution of $\mathrm{KNO}_{3}$, to achieve a loading of $10 \mathrm{wt} \%$ $\mathrm{KNO}_{3}$. After calcination, $\mathrm{K}_{2} \mathrm{Fe}_{4} \mathrm{O}_{7}$ and $\mathrm{K}_{2} \mathrm{Fe}_{22} \mathrm{O}_{34}$ were found in the samples, which showed signs of sintering and displayed a lower degree of porosity than the unmodified ore. Redox experiments were performed in a fluidized bed reactor at temperatures ranging from $750-900{ }^{\circ} \mathrm{C}$ with $\mathrm{CO}$ as feed followed by steam oxidations. A loading of $10 \mathrm{wt} \% \mathrm{KNO}_{3}$ significantly accelerated the reduction reaction and enabled a greater reduction degree of the iron oxide. Thus, higher amounts of hydrogen were obtained in the consecutive oxidations. Additionally by reducing the reduction time and increasing carbon conversion efficiency less coking occurred. The cycle stability was improved efficiently without the loss of produced hydrogen by maintaining a porous structure, whereas the unmodified ore lost $24 \%$ of its initial production capacity (Fig. 5).

\section{Bimetallic oxygen carrier}

Chiron et al. ${ }^{61}$ proposed the use of a bimetallic oxygen carrier to enable a synergetic effect of different redox behaviour of two metal oxides $\mathrm{CuO}$ and $\mathrm{Fe}_{2} \mathrm{O}_{3}$. In contrast to other metal oxides $\mathrm{CuO}$ is reduced by methane by releasing heat. Combining $\mathrm{CuO}$ with endothermic reacting metal oxides can reduce the external heat demand and lower the heat transfer requirement to the fuel reactor. Samples supported by $\mathrm{Al}_{2} \mathrm{O}_{3}$ consisting of either pure $\mathrm{Fe}_{2} \mathrm{O}_{3}$, pure $\mathrm{CuO}$ or a bimetal with varying compositions were prepared by an incipient wetness impregnation (IWI) and co-precipitation (CoPr) method. Most samples prepared by (CoPr) could not be fluidized since large slugs were observed that filled the entire cross-section of the reactor and an unsteady pressure drop occurred. Samples prepared by IWI were easily fluidized and reached their maximum solid conversion by steam oxidations significantly faster than samples prepared by CoPr. The bimetallic samples revealed a low solid conversion of approximately $10 \%$ irrespective of the preparation method. The highest conversion of $27 \%$ was measured with pure iron prepared by co-precipitation.

\section{$\mathrm{CoWO}_{4}$ as oxygen carrier}

$\mathrm{CoWO}_{4}$ has been reported as a suitable oxygen carrier for hydrogen production with methane as the reducing feed. ${ }^{62} \mathrm{De}$ los Ríos Castillo et al. ${ }^{63}$ impregnated cobalt tungstate $\mathrm{CoWO}_{4}$ with $\mathrm{Ni}$ and $\mathrm{La}_{2} \mathrm{O}_{3}$ to enhance its reactivity towards methane reduction. Reduction experiments at $850{ }^{\circ} \mathrm{C}$ with $\mathrm{CH}_{4}$ indicated improved reaction rates up to 6 and 2.5 times by the addition of $10 \mathrm{wt} \% \mathrm{Ni}$ and $10 \mathrm{wt} \%$ La respectively. However, the reactivity improvements diminished gradually at increasing reduction temperatures. In the second cycle the unmodified $\mathrm{CoWO}_{4}$ sample displayed higher reduction rates compared to the first cycle. This was related to the incomplete re-oxidation of Co by steam and the catalytic activity of the metal species. Nevertheless, samples promoted with $\mathrm{Ni}$ and La had improved reactivity but with smaller margins. Similar trends were reported regarding the activation energies. The inclusion of $\mathrm{Ni}$ and $\mathrm{La}$ significantly reduced the activation energy and thus improved reducibility. Again, the difference between the promoted samples and the reference sample disappeared after the first cycle.

\section{Perovskites}

Perovskite structured oxygen carriers are reported to have a good thermal stability and a high ionic and electronic conductivity. ${ }^{64,65}$ Zhao et al. ${ }^{66}$ studied three-dimensionally ordered macro-porous (3DOM) $\mathrm{LaFeO}_{3}$ and nano- $\mathrm{LaFeO}_{3}$ perovskite oxides synthesis gas and pure hydrogen using $\mathrm{CH}_{4}$ as fuel. 3DOM- $\mathrm{LaFeO}_{3}$ enabled a stable partial oxidation of methane at $850{ }^{\circ} \mathrm{C}$ in a fixed bed reactor over 10 cycles. An average methane conversion of $50 \%$ and the production of hydrogen by steam oxidation with small amounts of $\mathrm{CO}_{2}$ was achieved. The amount of released hydrogen decreased within the first 3 cycles but remained stable afterwards. The nano$\mathrm{LaFeO}_{3}$ enabled both a very high methane conversion $>90 \%$ and a high molar ratio $\mathrm{H}_{2} / \mathrm{CO}$ of 9 in the first cycles, which meant a high risk of carbon formation. Within 10 cycles the methane conversion decreased and ended up below the $3 \mathrm{DOM}-\mathrm{LaFeO}_{3}$ sample. The three-dimensional skeletal structure in the fresh sample gradually collapsed within repeated cycles caused by thermal and chemical stress. This led to a decrease in crystallinity and grain sizes, nevertheless a porous structure with little agglomeration was maintained, which preserved a stable cyclability. Zhao et al. ${ }^{67}$ further enhanced the performance of $\mathrm{LaFeO}_{3}$ perovskite oxides by doping with $\mathrm{Co}$, which is expected to increase the vacancies sites, thus improving the redox activity. ${ }^{68-70}$ Perovskite-type oxides $\mathrm{LaFe}_{1-x} \mathrm{Co}_{x} \mathrm{O}_{3}$ maintained their crystalline structure despite the doping with Co. An increasing Co content resulted in a higher concentration of oxygen vacancies, in a greater resistance to reduction and in a longer period of time required to reach a stable fuel conversion of $>90 \%$. Nevertheless, all sample compositions were completely reducible, indicated by the appearance of $\mathrm{La}_{2} \mathrm{O}_{3}$, $\mathrm{Fe}_{2} \mathrm{O}_{3}, \mathrm{FeO}, \mathrm{CoO}$ and Co. A Co molar ratio of 0.3 and 0.5 yielded the best performance regarding low risk of carbon formation, amount of produced hydrogen and stable $\mathrm{CH}_{4}$ conversion. Hence, $\mathrm{LaFe}_{0.7} \mathrm{Co}_{0.3} \mathrm{O}_{3}$ was used for consecutive redox cycling 
experiments. A steady feed conversion of $86 \%$ was achieved over 20 cycles with slight improvements within the first 5 cycles. A hydrogen production potential of $4 \mathrm{mmol} \mathrm{g}^{-1}$ was obtained with an average purity of $96 \%$. Post experimental analysis revealed degradation caused by sintering but these degradations were compensated by an increased oxygen vacancy concentration. Liang $^{\mathbf{6 4}}$ investigated the effects of $\mathrm{CeO}_{2}$ on perovskite supported iron oxides $\left(\mathrm{Fe}_{2} \mathrm{O}_{3} 15 \mathrm{wt} \%, \mathrm{CeO}_{2} 5 \mathrm{wt} \%, \mathrm{LaNiO}_{3}\right)$. The addition of cerium oxide slightly reduced the pore volume and pore diameter by partially filling void zones with $\mathrm{CeO}_{2}$. TPR experiments indicated a shift of the 3 iron oxide reduction peaks to lower temperatures, which suggests the promotion of the reduction reaction. In addition, the appearance of a fourth peak at $520{ }^{\circ} \mathrm{C}$ was observed, which corresponded to the reduction of $\mathrm{CeO}_{2}$. Redox experiments were executed in a fixed bed reactor at $800{ }^{\circ} \mathrm{C}$, consisting of a reduction with $\mathrm{CH}_{4}$, a steam oxidation and a final air oxidation. The reference sample without $\mathrm{CeO}_{2}$ exhibited a complete methane conversion and a stable hydrogen production. After 57 cycles, a sharp drop in the hydrogen yield was measured, which was a result of the decomposition of the perovskite structure, leading to isolated $\mathrm{Fe}_{3} \mathrm{O}_{4}$ and $\mathrm{FeO}$. The sample enhanced by $\mathrm{CeO}_{2}$ did not suffer from deactivation over 100 redox cycles, with a stable hydrogen yield slightly lower than the reference sample. The formation of a solid solution of $\mathrm{CeFeO}_{3}$ was observed, which increases the oxygen content and improves stability and activity.

He et al. ${ }^{71}$ used the perovskite $\mathrm{La}_{0.8} \mathrm{Sr}_{0.2} \mathrm{FeO}_{3-\delta}$ (LSF) as a supplement to iron oxide for a higher steam conversion efficiency during the steam oxidation step. $\mathrm{La}_{0.8} \mathrm{Sr}_{0.2} \mathrm{FeO}_{3-\delta}$ is harder to reduce but offers a high resistance to carbon deposition. A reactor with a two-layer filling was proposed, consisting of an iron oxide rich phase at the bottom with small amounts of LSF to prevent loss of stability by sintering and a LSF layer at the top (Fig. 6 right). Reduction reactions were executed with $\mathrm{CH}_{4}$ supplied from the top, which yielded an average methane conversion of $99 \%$ and a syngas production efficiency of $62 \%$. After the reduction the LSF layer consisted of $\mathrm{Fe}, \mathrm{La}_{2} \mathrm{O}$ and small amounts of $\mathrm{LaSrFeO}_{4-\delta}$. The oxidations were performed by

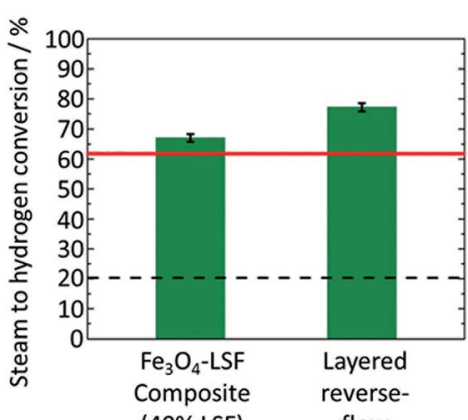

(40\% LSF)

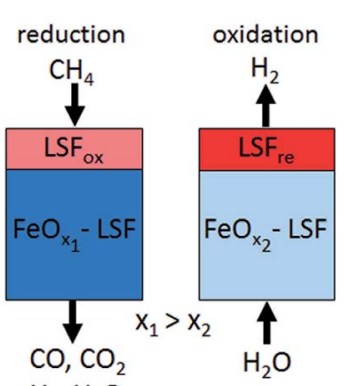

$\mathrm{H}_{2}, \mathrm{H}_{2} \mathrm{O}$
Fig. 6 Left: Steam to hydrogen conversion at $930{ }^{\circ} \mathrm{C}$. The red line displays the thermodynamically maximum conversion. Right: Schematic of the proposed layered reverse-flow redox process. ${ }^{71}$ Reproduced from, F. He and F. Li, Perovskite promoted iron oxide for hybrid water-splitting and syngas generation with exceptional conversion, Energy Environ. Sci., 2015, 8, 535-539, Copyright (2015), with permission from the Royal Society of Chemistry. supplying steam from the bottom, which initially oxidized the iron rich layer to iron oxide. The gas mixture, which consisted of $62.3 \% \mathrm{H}_{2}$ and $37.7 \%$ steam, was able to oxidize the upper layer further by forming $\mathrm{La}_{0.8} \mathrm{Sr}_{0.2} \mathrm{FeO}_{3-\delta}$ resulting in a total steam conversion of $77.2 \%$ and a hydrogen purity of $98.5 \%$ (Fig. 6 left). The higher steam conversion efficiencies are expected to significantly increase the process efficiency. The material characteristics with a high oxygen defect concentration of the LSF are responsible for the high affinity towards steam oxidation. The total amount of exchanged oxygen of the LSF was little compared to the iron rich layer, but the favourable thermodynamic equilibrium enabled a higher steam conversion efficiency. Galinsky et $a .^{33}$ reported significant reduction rate improvements by supporting iron oxide on LSF. Experiments were performed with $\mathrm{H}_{2}$, $\mathrm{CO}$ and $\mathrm{CH}_{4}$ in a TGA system. A faster reduction rate resulting in a higher degree of solid conversion and a high reactivity at lower temperatures were reported. Two material properties were attributed to the performance increases. Firstly, the electronic and ionic mixed conductivity enabled efficient transport of $\mathrm{O}^{2-}$-ions in the solid material and a full accessibility of bulk oxygen. Secondly, $\mathrm{Fe}_{2} \mathrm{O}_{3}$ crystallites with small grain sizes of $100 \mu \mathrm{m}$ were distributed evenly within the LSF support. Compared to $\mathrm{TiO}_{2}$ supported samples, a reduction rate acceleration of one magnitude was observed. The LSF samples indicated very high cycle stability with a capacity loss of $4 \%$ within 50 cycles.

\section{Oxygen carrier with spinel structures}

Spinel structured ferrites have been widely investigated widely in the last couple of years. Modifying physical and chemical properties by selecting suitable cations offers the prospect of preparing a specific oxygen carrier optimized for the selected application and a structural stability at high reaction temperatures and mechanical stress. ${ }^{72-75}$ Aston et al. ${ }^{29}$ investigated two mixed metal spinels, $\mathrm{NiFe}_{2} \mathrm{O}_{4}$ and $\mathrm{CoFe}_{2} \mathrm{O}_{4}$ prepared by incipient wetness method, with $\mathrm{ZrO}_{2}$ as substrate. The Ni ferrite and Co ferrite were expected to possess higher reducibility with $\mathrm{H}_{2}$ and $\mathrm{CO}$ and to be fully re-oxidized by steam. ${ }^{76}$ The reductions of the oxygen carriers were performed with syngas until a breakthrough of $\mathrm{H}_{2}$ and $\mathrm{CO}$ was observed. A period of full syngas conversion greater than $99 \%$ was visible, followed by a gradual increase of $\mathrm{H}_{2}$ and CO. The complete oxidation of the two spinel samples with steam took significantly longer than the oxidation of a pure iron reference sample. After an initial high steam conversion an extended transition phase with a low conversion efficiency was observed, which resulted in reaction times that were 3 times and 16 times longer for $\mathrm{CoFe}_{2} \mathrm{O}_{4}$ and $\mathrm{NiFe}_{2} \mathrm{O}_{4}$ respectively. Both samples were finally fully re-oxidized. Compared to pure iron a higher amount of hydrogen with a factor of 7-9 per mass of metal oxide can be generated, while maintaining a full syngas conversion during the reduction. However, in an industrial application the impact on the system efficiency due to the low steam conversion needs to be addressed.

$\mathrm{CoFe}_{2} \mathrm{O}_{4}$ spinel structured oxygen carriers using methanol as a reducing agent were investigated by Crocellà et $a l^{77}$ and 
Cocchi et al. ${ }^{78}$ Samples were prepared by co-precipitation and calcined at either $450{ }^{\circ} \mathrm{C}(\mathrm{CF} 450)$ or $750{ }^{\circ} \mathrm{C}$ (CF750). In the first reduction cycle at $300^{\circ} \mathrm{C}$ the CF450 exhibited significantly faster reduction rates compared to $\mathrm{CF} 750$ and reached a complete solid conversion, which was attributed to a higher active surface and the presence of larger amounts of surface octahedral sites. In both samples the formation of iron carbide $\mathrm{Fe}_{3} \mathrm{C}$ was detected, which decomposed to Fe and solid carbon and acted as a carbon source during the steam oxidation. The amount of $\mathrm{Fe}_{3} \mathrm{C}$ increased with the reaction time and the formation was intensified at higher temperatures. When comparing the influence of the different calcination temperatures, it was found that the ratio between the $\mathrm{Fe}_{3} \mathrm{C}$ and the CoFe alloy was lower in the CF750 sample. Several consecutive redox cycles indicated that the CF450 sample underwent irreversible structural changes, which resulted in an increase in crystallinity and loss of active octahedral sites, while the CF750 retained its structural origin state. Eventually, both samples possessed similar structural attributes. After the steam oxidations the presence of $\mathrm{Fe}_{3} \mathrm{O}_{4}$ was found, which revealed that a full recovery of the oxidized state was not possible, due to kinetic restrictions. Additionally, an incomplete removal of carbon was visible, meaning that an accumulation over several cycles occurred. This oxidation behaviour suggested that a final air oxidation is required to remove solid carbon and to regenerate the oxygen carrier. Trevisanut et al. ${ }^{79}$ analysed the spinel $\mathrm{NiFe}_{2} \mathrm{O}_{4}$ as an oxygen carrier using ethanol as a reducing agent. Samples prepared by co-precipitation were studied in a fixed bed reactor at $450{ }^{\circ} \mathrm{C}$. A high ethanol conversion, close to $100 \%$, and a high activity was reported. The $\mathrm{NiFe}_{2} \mathrm{O}_{4}$ oxygen carriers led to a higher amount of fully oxidized components compared to pure iron oxide, which suggests greater accessibility of surface oxygen. The spinel sample enabled an enhanced reduction rate, despite it having similar surface areas to $\mathrm{Fe}_{3} \mathrm{O}_{4}$. Hence, the redox reactivity might be attributed to an increased mobility of bulk oxygen. The presence of separated $\mathrm{Ni}$ and NiFe alloy was observed after a steam oxidation at $450{ }^{\circ} \mathrm{C}$, indicating an incomplete oxidation due to slow oxidation kinetics. Hydrogen was obtained with significant amounts of $\mathrm{CO}_{2}$ and $\mathrm{CO}$, which were related to carbon formation during the reduction. Sample analysis reassured the presence of iron carbides and solid carbon during the reduction. To overcome this incomplete steam oxidation Vozniuk et al. ${ }^{80}$ prepared binary and ternary ferro-spinels $\mathrm{M}_{0.6-x}^{1} \mathrm{M}_{x}^{2} \mathrm{Fe}_{2.4} \mathrm{O}_{y}$ using Co and Mn with different atomic ratios from $x=0$ to 1 . Samples with uniform morphology and particle size distribution were obtained. The integration of the metal cations strongly modified the reducibility towards hydrogen by changing the structural characteristics and the oxygen mobility. Direct ethanol reduction experiments in a fixed bed quartz reactor identified acetates and carbonates as the primary intermediates of the redox reaction if Co modified oxygen carriers were used, while samples with solely $\mathrm{Mn}$ as additives exhibited a complete absence of carbonates and a reduced reactivity. An initial complete ethanol conversion was achieved with all oxygen carrier samples. The concentrations of $\mathrm{CO}_{2}$ and $\mathrm{CO}$ suggested that the partial oxidation of ethanol was the main reduction route. Acetone, which indicated the aldol reaction route and the decomposition of ethanol to acetaldehyde was detected in the beginning and decreased over time. With the ongoing experiments the amount of coke and higher hydrocarbons was increasing due to the limitation of exchangeable oxygen in the oxygen carrier. It was concluded that the modification of Co improves the reducibility of oxygen carriers with ethanol, while Mn enhanced the resistance to coking, but did not completely exclude it. $\mathrm{Co}_{0.3} \mathrm{Mn}_{0.3^{-}}$ $\mathrm{Fe}_{2.4} \mathrm{O}_{y}$ was identified as the most promising candidate because of its high hydrogen yield during reduction and a significantly reduced carbon formation. The complete carbon conversion was not achieved during the oxidation, which still required a final carbon removal step by air. Kuo et al. ${ }^{81}$ investigated a nickel aluminium spinel ferrite $\mathrm{NiFeAlO}_{4}$ as oxygen carrier for hydrogen generation. After a calcination temperature of $1300^{\circ} \mathrm{C}$ a single cubic spinel phase of $\mathrm{NiFeAlO}_{4}$ was observed with a crystalline size distribution between 100-300 nm. After a complete reduction $\mathrm{Al}_{2} \mathrm{O}_{3}$ and the bimetal FeNi was formed, which possessed a high porosity and efficiently prevented agglomeration by a large triple phase boundary area. The oxygen carrier was submitted to 10 consecutive redox cycles to investigate the cycle stability. The amount of weight loss increased within the first four cycles, possibly by the formation of additional pores by the phase changes and finally stabilized without any signs of degradation. A slight decrease of the redox reaction rate was observed. The steam oxidation yielded hydrogen and a phase mixture of $\mathrm{Ni}, \mathrm{Fe}_{3} \mathrm{O}_{4}$ and $\mathrm{Al}_{2} \mathrm{O}_{3}$, which was oxidized by air to the original spinel phase. Bhavsar et al. ${ }^{82}$ focused on preparing a nanostructured oxygen carrier support based on barium hexaaluminate (BHA). A carrier structure with a high porosity and sponge-like nanostructure, which suppressed migration and prevented sintering, was obtained. Depending on the application, a selected active metal oxide can be embedded as nano-particles in the support material. In case of chemical looping hydrogen production nano-sized iron particle were applied (Fig. 7). The carrier showed a high stability at temperatures up to $900{ }^{\circ} \mathrm{C}$ without any signs of deactivation. Redox reaction revealed similar reduction rates compared to conventional oxygen carrier supports, however, significantly

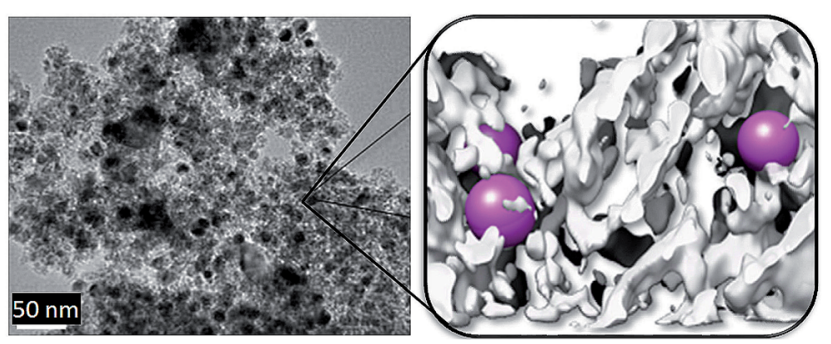

Fig. 7 Left: TEM image of a Ni-BHA nanostructured carrier (Ni 40 wt\%). Right: 3D tomographic reconstruction of the carrier nanostructure from a set of TEM slices. The white structure represents the $\mathrm{BHA}$ carrier with the embedded metal nanoparticles shown as pink spheres.$^{82}$ Reprinted and adapted from S. Bhavsar, M. Najera, R. Solunke, and G. Veser, Chemical looping: to combustion and beyond, Catal. Today, 2014, 228, 96-105, Copyright (2013), with permission from Elsevier. 


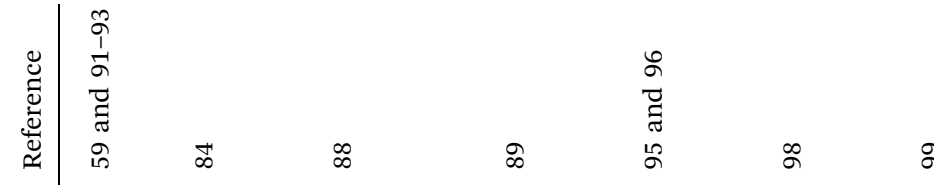

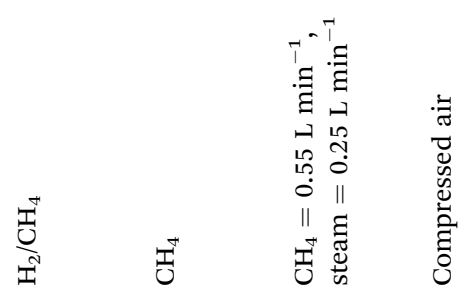


accelerated oxidation rates were measured. The steam oxidation rates were further improved by decreasing the particle sizes from $54 \mathrm{~nm}$ to $16 \mathrm{~nm}$.

\section{Reactor design}

Two reactor designs, the fixed bed reactor and the fluidized or moving bed, were successfully operated and presented in the surveyed literature (summarised in Table 2). The fixed bed reactor system is operated in batch mode by switching the operation gases. The oxygen carrier is kept in place, while the reduction and the oxidation reactions are executed consecutively. This enables a design with a low degree of complexity due to the absence of moving parts. High purity hydrogen is obtained because the carbon containing fuel streams and the hydrogen stream are completely separated. The fluidized or moving bed system circulates the oxygen carrier between separated reactors or reactor sections. The moving solid material increases the system complexity and mechanical strain, however, the higher technological complexity enables several beneficial properties. In contrast to a fixed bed reactor these systems are operated in continuous mode and thus enable an (i) uninterrupted hydrogen production combined with pure separated streams of $\mathrm{CO}_{2}$ and $\mathrm{N}_{2} \cdot{ }^{30,83,84}$ In each reactor the same reaction, either reduction or oxidation, is performed, which permits (ii) a specific reactor layout regarding materials, design and operation parameters to optimize gas yield and solid conversion. ${ }^{85-89}$ (iii) The solid materials, which suffer from cycle stability can be continuously replaced during normal operation modes. (iv) The oxygen carrier can participate in the heat management of the system by delivering heat from the exothermic oxidations to the endothermic reduction and thus reduce the required amount of external heat. ${ }^{83,90}$ However attrition losses due to movement of the solids and a lower hydrogen purity caused by the gas slip between the reactors are to be excepted. ${ }^{84,89}$

A $25 \mathrm{~kW}_{\text {th }}$ sub-pilot syngas for syngas chemical looping (SCL) was introduced by Ohio State University (Fig. 8 left)..$^{59,91-93}$ Sridhar et al. ${ }^{91}$ discussed the adaption of the system to a threereactor iron based system for the co-generation of pure hydrogen and electricity. The fuel reactor and the steam reactor were operated in a co-current moving bed system and a fluidized bed air reactor, which acted as a riser. The reactors were separated by a system of two ball valves. The solid flow rate was controlled with a rotary disc feeder. Experiments were performed with syngas $\left(\mathrm{CO} / \mathrm{H}_{2} 2 / 1\right.$ flow rate $\left.15 \mathrm{~L} \mathrm{~min}^{-1}\right)$ at $900{ }^{\circ} \mathrm{C}$ and a solid flow of $150 \mathrm{~g} \mathrm{~min}{ }^{-1}$. First operations demonstrated that a hydrogen production with an average purity of $94.5 \%$ and in situ carbon capture is feasible in this system. Tong et al. ${ }^{92}$ optimized operation parameters and investigated the redox performance of two iron based oxygen carriers with $2 \mathrm{~mm}$ and $4.5 \mathrm{~mm}$ diameters during a total operation of 300 hours. Both samples provided sufficient high cycle stability, whereas the smaller particles possessed a faster reaction rate, probably due to the higher surface area. Both samples performed similarly well regarding syngas conversion and hydrogen purity. The smaller particles had a lower fluidizing velocity and required
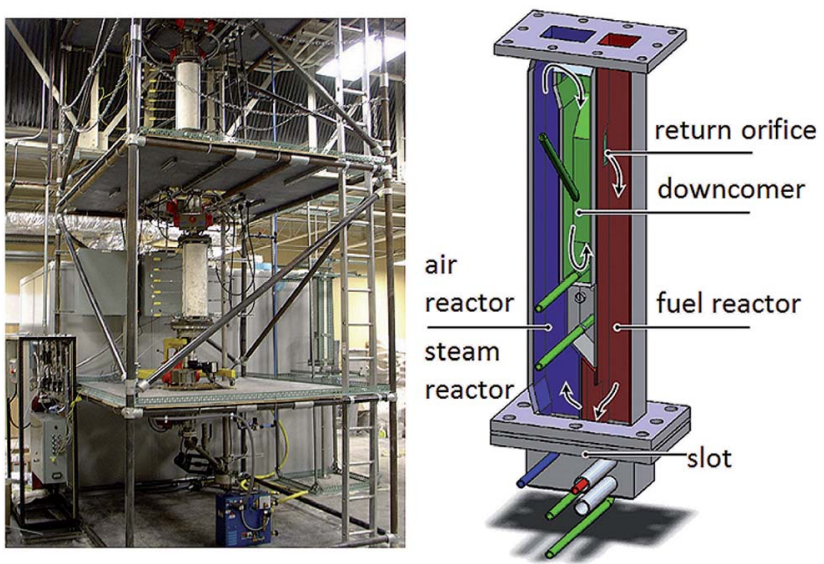

Fig. 8 Left: Photo of the $25 \mathrm{~kW}$ th sub-pilot SCL unit at The Ohio State University. ${ }^{59}$ Right: Schematic representation of the two-compartment fluidized-bed reactor proposed by Rydén et al. ${ }^{84}$ Reprinted and adapted from A. Tong, S. Bayham, M. V Kathe, L. Zeng, S. Luo, L.-S. Fan, and W. G. Lowrie, Iron-based syngas chemical looping process and coal-direct chemical looping process development at Ohio State University, Appl. Energy, 2014, 113, 1836-1845, Copyright (2013), with permission from Elsevier. Reprinted and adapted from $M$. Rydén and $M$. Arjmand, Continuous hydrogen production via the steam-iron reaction by chemical looping in a circulating fluidized-bed reactor, Int. J. Hydrogen Energy, 2012, 37, 4843-4854, Copyright (2013), with permission from Elsevier.

less air in the rise to be transported. Hence, smaller oxygen carriers are expected to show better flow properties and a higher resistance to attrition. System improvements by reducing gas leakage between the reactors were achieved by replacing mechanical seals ${ }^{91}$ with a non-mechanical valve consisting of a standpipe with injected nitrogen. ${ }^{92}$ Furthermore, a gas preheater for the synthesis gas feed was installed to prevent carbon deposition at lower temperatures and a dual syngas injection was added to optimize to axial gas concentration profile and increase the syngas conversion from $78.34 \%$ to $92.23 \%$. A final hydrogen purity $>99 \%$ at steady conditions was obtained. The system was also operated using methane with a feed conversion of $99.99 \%$ while maintaining a high oxygen carrier conversion of $32.50 \% .^{93} \mathrm{~A}$ reduced solid flow rate increased the reduction degree to $48.82 \%$, however the $\mathrm{CH}_{4}$ conversion dropped to $80.35 \%$. The results suggested that a complete fuel conversion is predefined by a critical solid/gas flow ratio. Flow ratios that exceed this ratio result in a nonreacting zone in the top of the moving bed. The countercurrent moving bed used in this system is expected to increase the oxygen carrier conversion by up 5 times compared to a co-current fluidized bed systems with $11 \% .^{59,94}$ In an experimental investigation lasting 2 hours, an oxygen carrier conversion in the reducer reactor of $35.54 \%$, related to the theoretical value of $39.6 \%$, was achieved, while maintaining a syngas conversion of $>99 \% .{ }^{91}$ Based on previous results with a syngas feed, the $25 \mathrm{~kW}_{\text {th }}$ sub-pilot unit was utilized for the coal direct chemical looping process (CDCL) in continuous operation lasting 200 hours. A coal conversion ranging from $90-99 \%$ with an average conversion of $99.7 \%$ was obtained. These 
experiments were not combined with the steam oxidizer, hence no conclusion can be drawn on the possible hydrogen purity, however, combustor gas analysis for carbon sequestration indicated $\mathrm{CO}_{2}$ purity of $99.7 \%$ with $\mathrm{CO} 0.2 \%$ and $\mathrm{CH}_{4} 0.1 \%$ as the main impurities. ${ }^{59}$

Rydén et $a l .{ }^{84}$ examined a two-compartment fluidized bed reactor for hydrogen production at temperatures between 800$900{ }^{\circ} \mathrm{C}$ (Fig. 8 right). The system with $300 \mathrm{~mm}$ in height consisted of a steam reactor $(25 \times 25 \mathrm{~mm})$ which transported the oxygen carrier upwards to the down-comer, where the particles passed into a J-type loop-seal and were transferred to the fuel reactor through an orifice. The fuel reactor was operated as a bubbling bed. At the bottom, the oxygen carrier returned past a U-type slot to the steam reactor and closed the circle. Experiments were executed with syngas or CO as feed (0.5-1.25 L $\min ^{-1}$ ) and steam (4.0-5.0 L $\left.\mathrm{min}^{-1}\right)$ as oxidant. An iron based oxygen carrier ( $60 \mathrm{wt} \% \mathrm{Fe}_{2} \mathrm{O}_{3}$ and $40 \mathrm{wt} \% \mathrm{MgAl}_{2} \mathrm{O}_{4}$ ) in the diameter range of 90-250 $\mu \mathrm{m}$ was applied. The operation started with a full conversion of the fuel due to the presence of $\mathrm{Fe}_{2} \mathrm{O}_{3}$. After the initial reduction to $\mathrm{Fe}_{3} \mathrm{O}_{4}$, $\mathrm{CO}$ an incomplete conversion was observed due to reduction stage of $\mathrm{Fe}_{3} \mathrm{O}_{4}$ to $\mathrm{FeO}$. Particles reduced to $\mathrm{FeO}$ were transferred to the steam reactor. A stable operation without problems of de-fluidization was maintained for up to 4 hours with a gas conversion between 75$80 \%$, which increased with a decreasing fuel flow. These results were slightly higher than expected by thermodynamic predictions, probably caused by gas leaking from the fuel reactor into the steam reactor. In the steam reactor the $\mathrm{FeO}$ particles were oxidizing with a hydrogen production rate of $0.5 \mathrm{~L} \mathrm{~min}^{-1}$, which matched the theoretically value as long as the fuel gas flow was kept at low values. The impurities $\mathrm{CO}_{2}$ 19\% and CO 5\% were detected in the hydrogen as a results of gas leakage.

Moghtaderi ${ }^{\mathbf{9 5 9 6}}$ developed a miniaturized chemical looping steam reformer CLSR in micro-reactor assembly, which is suitable for on-board mobile fuel enrichment with hydrogen (Fig. 9 right bottom). The miniaturized system is expected to show improvements compared to conventional designs with regard to (i) volumetric productivity, (ii) safety issues, (iii) operation costs, (iv) scalability, (v) pressure drop and (vi) surface-to-volume-ratio. The micro-reactor assembly used in the experiments consisted of a single stainless steel plate with a zigzag shaped engraving $(0.05 \mathrm{~m}$ length, cross section area: $200 \times 100 \mu \mathrm{m})$ (Fig. 9 right top). $\mathrm{Fe}_{3} \mathrm{O}_{4}$ on alumina support with a layer thickness of $1 \mu \mathrm{m}$ and a particle size of $20-40 \mu \mathrm{m}$ was utilized as an oxygen carrier. Reduction experiments at $900{ }^{\circ} \mathrm{C}$ with methane resulted in a rapid reduction to $\mathrm{FeO}$ and the formation of solid carbon by catalytic decomposition of methane. The consecutive steam oxidations started with an initially fast oxidation rate, which decreased significantly at a solid conversion of $80 \%$. The complete oxidation took approximately 4 times longer than the reduction. A series of 4 reactors was proposed, each consisting of one $\mu$-CLSR unit as described before, to equalize the different reaction times and compensate for the longer oxidations. The proposed operation procedure consisted of consecutively executed reductions and simultaneously performed oxidations in the 4 reactors. The experimental results suggested that, within the timeframe of 48

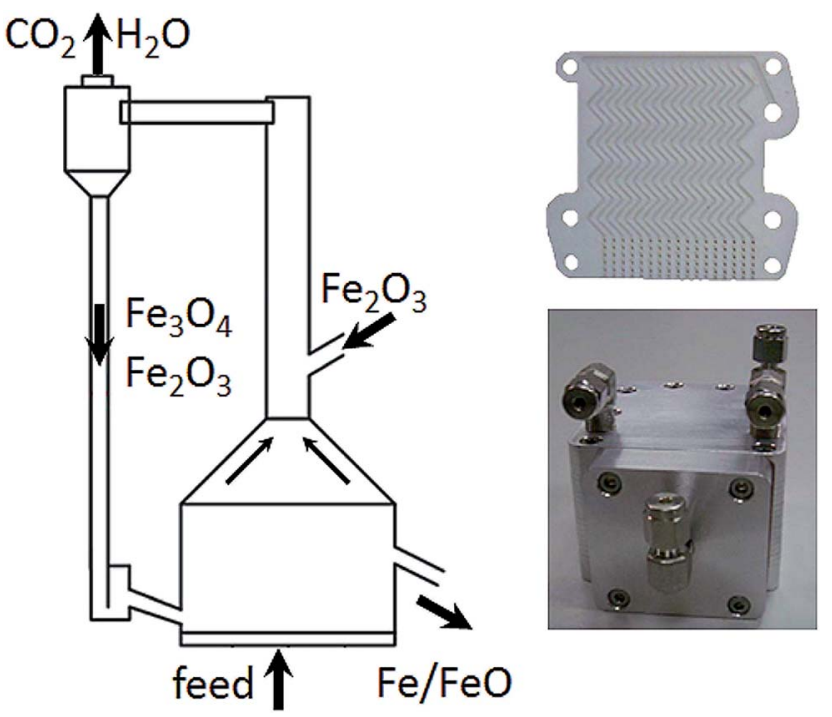

Fig. 9 Left: Schematic representation of the two-staged fluidized-bed system by Xue et al. ${ }^{88} \mathrm{~A}$ single reactor plate with the zigzag shaped pattern (right top) utilized in the CLSR micro-reactor (right bottom) proposed by Moghtaderi. ${ }^{95}$ Reprinted and adapted with permission from Z. Xue, S. Chen, D. Wang, and W. Xiang, Design and fluid dynamic analysis of a three-fluidized-bed reactor system for chemical-looping hydrogen generation, Ind. Eng. Chem. Res., 51, 4267-4278, Copyright (2012) American Chemical Society. Reprinted and adapted with permission from B. Moghtaderi, Hydrogen enrichment of fuels using a novel miniaturised chemical looping steam reformer, Chem. Eng. Res. Des., 2012, 90, 19-25, Copyright (2011) The Institution of Chemical Engineers, Published by Elsevier B.V

seconds, a solid conversion degree of $30 \%$ in all participating $\mu$ reactors was achieved followed by a complete re-oxidation yielding a hydrogen product stream with $96 \%$ purity. Thus, the layout of $2 \times 4$ reactors enables a continuous production of hydrogen in a $\mu$-CLSR system.

Xue et $a l .{ }^{88}$ developed a three-reactor fluidized-bed system in the range of $50 \mathrm{~kW}$. The system was constructed and operated as a cold-flow model. A fluidized fuel reactor was proposed as a key component, which consisted of a base bubbling bed at low velocity and an upper fluidized bed at high velocity (Fig. 9). ${ }^{\mathbf{8 7 , 8 8 , 9 7}}$ $\mathrm{Fe}_{3} \mathrm{O}_{4}$ particles entering near the bottom bubbling bed react with the fresh fuel gas and leave the reactor in reduced state at the bottom. The reduction of $\mathrm{Fe}_{3} \mathrm{O}_{4}$ takes significantly longer than the reduction of $\mathrm{Fe}_{2} \mathrm{O}_{3}$, thus a sufficiently large bubbling bed guarantees the required residence time in the bottom part to ensure a desired solid conversion. The partially reacted fuel gas moves through the upper reactor section, where $\mathrm{Fe}_{2} \mathrm{O}_{3}$ particles from the oxidizer are supplied. The $\mathrm{Fe}_{2} \mathrm{O}_{3}$ particles are partially reduced by completely converting the reduction gas to $\mathrm{H}_{2} \mathrm{O}$ and $\mathrm{CO}_{2}$. The fuel reactor design was successfully operated for 600 minutes using aqueous bio-oil. ${ }^{87}$ Xue et al. ${ }^{88}$ integrated the reactor into a $50 \mathrm{~kW}$ three-fluidized-bed reactor system to investigate operation parameters and solid circulation characteristics. The main design values were an operation temperature of $900{ }^{\circ} \mathrm{C}$, methane as fuel, a particle size of 100-305 $\mu \mathrm{m}$, a solid inventory of $5 \mathrm{~kg}$ and gas flows between $24-31 \mathrm{Nm}^{3} \mathrm{~h}^{-1}$. Coldflow operations were performed with He/air in all three 
reactors with glass beads as particles. By varying the gas flows and changing the fluidizing conditions, the solid circulation rate was manipulated. It was found that the solid circulation rate influenced the gas leaks between the reactors, which is of high importance regarding hydrogen purity and $\mathrm{CO}_{2}$ emissions. The cold flow operations were performed in long-term operation tests with stable pressure conditions.

Cho et al. ${ }^{98}$ constructed a $300 \mathrm{~W}_{\text {th }}$ three-reactor chemical looping system to produce high purity hydrogen out of methane. Steady solid circulation operation, using $\mathrm{Fe}_{2} \mathrm{O}_{3}$ supported with $\mathrm{ZrO}_{2}$ with a diameter of 125-300 $\mu \mathrm{m}$, was executed for 13 hours. ${ }^{36}$ The solids showed no agglomeration and only small signs of thermal sintering, which suggested a high durability. An average methane conversion of $94.15 \%$ at $900{ }^{\circ} \mathrm{C}$ was achieved. Fuel flow analysis indicated that a high methane conversion is possible as long as a moving bed regime is maintained. A transition to a fluidized bed reduced the methane conversion to below $90 \%$. Hydrogen with a purity of $99.95 \%$ was produced at $800{ }^{\circ} \mathrm{C}$ with minor CO contaminations, when reducing the oxygen carrier to $\mathrm{FeO}$. $\mathrm{CH}_{4}$ was not detected, which suggested that gas leakage into the steam reactor was negligible. The $\mathrm{H}_{2}$ production rate was approximately $63 \%$ below the theoretical value due to a non-uniform flow pattern. The formation of carbon was investigated under the deep reduction of the oxygen carrier by lowering the solid flow. The higher amount of completely reduced iron catalysed the deposition of solid carbon. A higher amount of produced hydrogen with a significantly reduced purity was observed, as a result of the oxidation of carbon with steam.

Hong et al. ${ }^{99}$ studied the solid flow characteristics of zirconia beads (mean diameter $186 \mu \mathrm{m}$ ) in a multi stage moving bed system. The gas flows into the loops seals were varied to investigate the changes in the flow pattern, the solid mass flux

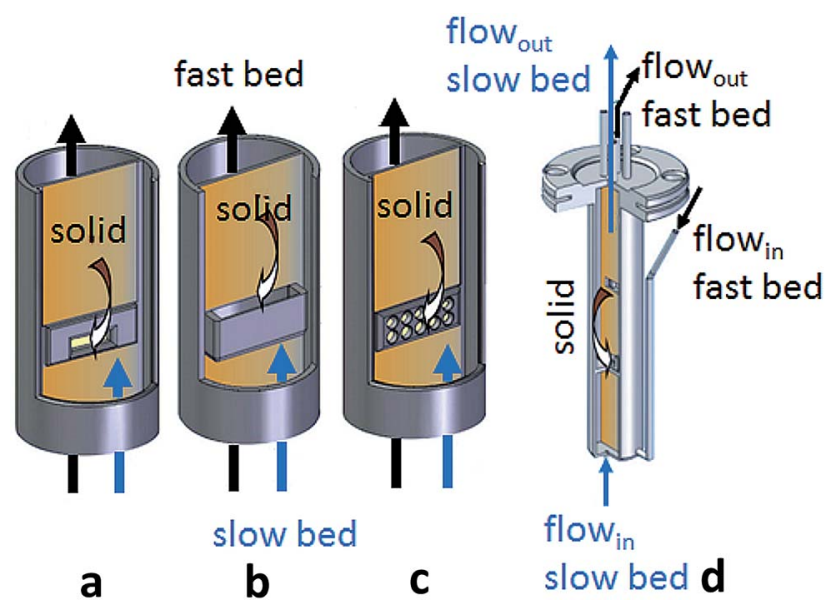

Fig. 10 Schematic of different connecting devices (a) rectangular connection, (b) J-connection, and (c) orifice connection. Schematic representation of the fluidized-bed system (d) by Herguido et al. ${ }^{89}$ Reprinted and adapted from J. Herguido, J. Peña, and E. Carazo, Experimental assessment of hydrogen separation from $\mathrm{H}_{2} / \mathrm{H}_{4}$ mixtures by the "steam-iron process" in an interconnected circulating fluidized bed reactor, Int. J. Hydrogen Energy, 2014, 39, 14050-14060, Copyright (2014), with permission from Elsevier. and the solid mean residence time at ambient temperatures. In the moving bed regime the solid mass flux and the pressure drop increased with a rising gas flow in the loop seal. A stable pressure profile was maintained. The higher gas flow correlated with a growing bed height but lowered the mean residence time of the solid particles because of an enlarged solid mass flux. A further increase of the gas flow changed the flow pattern to a bubbling flow, and finally to a slug flow characteristic. The flow patterns had little effect on the solid mass flux but resulted in significant pressure deviations. As long as a moving bed regime was maintained the solid flux pattern remained similar at different temperatures, however higher gas velocities and a higher solid flow rate were measured. Lee et al. ${ }^{\mathbf{1 0 0}}$ concluded that a riser is required as a $4^{\text {th }}$ module to increase the stability of the system. The selected operation conditions of gas velocities and solid circulation rate enabled a stable pressure profile and prevented gas leakage between the reactors.

Herguido et al. $^{89}$ introduced a single reactor with two interconnected beds, a slow reduction bed with $\mathrm{H}_{2} / \mathrm{CH}_{4}$, and a second fast bed for steam oxidation (Fig. 10d). Oxygen carrier with particle size of 150-200 $\mu \mathrm{m}$ mixed with silica sand were applied. The two beds are connected with two slits at the bottom and the top. Redox experiments were performed at $550{ }^{\circ} \mathrm{C}$. Three designs of interconnections between the two beds in respect to gas leakage were evaluated, a rectangular slit, a Jconnection and an orifice connection (Fig. 10a-c). The orifice connection with a hole-diameter of $0.3 \mathrm{~cm}$ and an open area of $0.4 \mathrm{~cm}^{2}$ showed a more superior performance than the other design variations. The gas leakage was successfully minimized by reducing the gas velocity difference in the two fluidized beds.

\section{Process development}

Chemical looping technologies for hydrogen generation are usually operated with a reducing synthesis gas provided by external processes, e.g. from coal gasification or methane reforming. However, recent work has shown that the process can be easily modified to handle a variety of feedstocks, including unconventional resources, either by direct reduction or by the incorporation of the chemical looping system with syngas conversion processes. Herguido et al. ${ }^{89}$ investigated the applicability of the chemical looping process for the separation of a mixture of hydrogen and methane. A reactor with two interconnected fluidized beds and an iron based oxygen carrier were used for the fuel processing. Reactions were executed in a temperature range of $500-550{ }^{\circ} \mathrm{C}$ and with hydrogen fractions between $0.35-0.65$. The operation conditions enabled a reduction of iron oxide with hydrogen but left methane and other impurities inert. An average hydrogen conversion of $20 \%$ was obtained with little influence of the varied parameters (gas velocity, relative velocity and hydrogen content), which suggested that the separation performance is mainly limited by thermodynamic restrictions. The separations system was tested for $44 \mathrm{~h}$ and enabled the production of pure hydrogen without carbon contaminations. Small amounts of solid carbon were found in the reactor after the operation, thus coke remained 
inert during the experiments at the selected oxidation conditions.

\section{Alcohols as feedstock}

The same group investigated ethanol ${ }^{101}$ and methanol ${ }^{102}$ as feed in a fixed bed reactor. $\mathrm{Fe}_{2} \mathrm{O}_{3}$ supported with $\mathrm{CeO}_{2}$ and $\mathrm{Al}_{2} \mathrm{O}_{3}$ was used as the oxygen carrier. Higher temperatures and a higher ethanol partial pressure (0.05-0.15 bar) accelerated the reduction rates. However, an increased reduction temperature led to a slower re-oxidation rate in the consecutive steam oxidation, most likely caused by thermal sintering of the particles. The reductions of the alcohol feeds revealed 3 stages: (i) the reduction of $\mathrm{Fe}_{2} \mathrm{O}_{3}$, (ii) the reduction of $\mathrm{Fe}_{3} \mathrm{O}_{4}$ to $\mathrm{Fe}$ and (iii) a stable thermal decomposition of ethanol and methanol. A higher reduction degree of the solid led to a higher amount of partially oxidized components ( $\mathrm{CO}$ and $\mathrm{H}_{2}$ ) and a lesser amount of fully oxidized components $\left(\mathrm{H}_{2} \mathrm{O}\right.$ and $\left.\mathrm{CO}_{2}\right)$. The gas composition converged towards the theoretical values of thermal decomposition products after the full reduction of the oxygen carrier. Solid carbon formation occurred in all three stages and was verified by the detection of structured nanotubes after the experiments. The formation of iron carbide, which decomposed to iron and solid carbon, was promoted at $450{ }^{\circ} \mathrm{C}$ after the reduction to metallic iron. A process with short-time looping steps may avoid the carbide formation and thus limit the amount of solid carbon to minimize the carbon contaminations. ${ }^{103}$ The methanol reduction showed a significantly higher carbon deficit in the carbon balance, which correlated with higher amounts of coke at lower temperatures. ${ }^{102}$ The consecutive oxidations with steam at $500{ }^{\circ} \mathrm{C}$ produced hydrogen with little $\mathrm{CO}$ and $\mathrm{CO}_{2}$ contaminations (below $1 \mathrm{ppm}$ ) in the case of ethanol as feed and no carbon impurities using methanol (50 ppm detection limit). Hence, coke remained mostly inert on the solid particles. Several consecutive cycles suggested that the advisable reaction temperature for ethanol and methanol is 675 ${ }^{\circ} \mathrm{C}$ and $700{ }^{\circ} \mathrm{C}$ respectively. At these temperatures the smallest decay of the oxygen carrier, while providing a sufficient fast reduction rate, was observed. Coke formation occurred over to complete temperature range with both feeds, which demands a decoking step after several cycles to prevent carbon accumulation. ${ }^{101-103}$ TPR reduction analysis of three iron oxides, hematite, goethite and magnetite using low concentrations of ethanol in nitrogen was performed by Rosmaninho et al. ${ }^{104}$ All samples revealed the reduction intermediates $\mathrm{Fe}_{3} \mathrm{O}_{4}$ and $\mathrm{FeO}$ before the complete reaction to $\mathrm{Fe}$, irrespective of the initial oxidation state. In all cases the ethanol conversion started at a temperature of $300{ }^{\circ} \mathrm{C}$. The complete conversion of ethanol was reached according to the accessibility of surface oxygen. Hence, hematite and goethite enabled a complete ethanol transformation between $350-400{ }^{\circ} \mathrm{C}$, whereas the application of magnetite required a temperature beyond $500{ }^{\circ} \mathrm{C}$ to achieve a complete conversion. At $700{ }^{\circ} \mathrm{C}$, a complete reduction of the oxygen carrier to iron was observed. A further temperature increase led to a significant formation of solid carbon and iron carbide, thus $700{ }^{\circ} \mathrm{C}$ was identified as the most suitable reaction temperature to achieve a complete reduction and to minimize the deposition of carbon. The oxidation with steam re-oxidized the oxygen carrier to magnetite with small amounts of hematite and wustite. Consecutive redox cycles revealed a degradation of the oxygen carrier, which led to an incomplete reduction and a reduced amount of produced hydrogen of $70 \%$ after 5 cycles.

\section{Process combination of reforming of hydrocarbons with CLWS}

Plou et al. and Herrer et al. combined the catalytic dry reforming with the chemical looping hydrogen in a single reactor bed. ${ }^{\text {105-107 }}$ As a solid mixture a triple oxide oxygen carrier $\left(\mathrm{Fe}_{2} \mathrm{O}_{3}\right.$ supported with $\mathrm{CeO}_{2}$ and $\left.\mathrm{Al}_{2} \mathrm{O}_{3}\right)$ and a nickel based catalyst $\left(\mathrm{NiO} / \mathrm{NiAl}_{2} \mathrm{O}_{4}\right.$ with an excess of $\mathrm{NiO}$ of $10 \mathrm{wt} \%$ ) was applied with a weight ratio of OC/catalyst of $85 / 15 \mathrm{wt} \%$. Experiments were performed with different biogas compositions $\mathrm{CH}_{4} / \mathrm{CO}_{2} 50 / 50-65 / 35$ at temperatures from $600-750{ }^{\circ} \mathrm{C}$. Three stages were visible in the fixed bed reductions, which were analysed in detail. The reaction started with a high methane conversion directly followed by a conversion minimum. This phase was initially dominated by the reduction of $\mathrm{Fe}_{2} \mathrm{O}_{3}$ to $\mathrm{Fe}_{3} \mathrm{O}_{4}$ and the full oxidation of the feed to $\mathrm{CO}_{2}$ and $\mathrm{H}_{2} \mathrm{O}$. After the consumption of the lattice oxygen of $\mathrm{Fe}_{2} \mathrm{O}_{3}$ the reduction of $\mathrm{NiO}$ to Ni occurred, which was indicated by the appearance of $\mathrm{H}_{2}$ and $\mathrm{CO}$. The presence of elemental $\mathrm{Ni}$ enabled the catalytic dry reforming of methane to produce a stable fraction of $\mathrm{CO}$ and $\mathrm{H}_{2}$ in combination with the deep reduction of $\mathrm{Fe}_{3} \mathrm{O}_{4}$ to iron. Once the oxygen carrier was completely reduced, the solely catalytic dry reforming of biogas was observed. An increasing reaction temperature enhanced the reaction rates and the transition to the stable reforming stage, whereas an increased $\mathrm{CH}_{4}$ ratio slightly accelerated the transition between the stages. The comparison of experimental data with theoretical data showed good accordance for the dry reforming but a constant deviation regarding the iron oxide reduction reaction, which suggests diffusion limitations hindering the mass transfer. The formation of coke by $\mathrm{CH}_{4}$ decomposition indicated by a too high amount of measured hydrogen and thus the deactivation of the catalysts by blocking of active catalytic sites was observed. The effect was enhanced with increasing $\mathrm{CH}_{4}$ fractions. Post reaction analysis reported the presence of graphitic carbon ${ }^{105,107}$ and highly amorphous carbon. ${ }^{106}$ Coke was only present on the nickel particles, which explained the catalytic degradation. During purging phases with inert gas a mass loss was observed, which increased with higher temperatures. This suggested a solid-solid decoking reaction between the incompletely reduced oxygen carriers and the solid carbon and explained the absence of coke on the oxygen carrier in the post experimental analysis. The oxidations with steam at $500{ }^{\circ} \mathrm{C}$ produced hydrogen with a purity of $>99 \%$ with carbon dioxide as impurity. The main part of the carbon depositions remained inert during the steam oxidation, and thus accumulates over consecutive cycles without a regeneration step. ${ }^{\mathbf{1 0 2 , 1 0 6 - 1 0 8}}$ A combination of a catalytic steam reforming and the chemical looping hydrogen process in one reactor with two adjacent fixed bed was investigated by Nestl et al. ${ }^{109}$ Investigations of methane reforming were executed, varying temperature, pressure and the S/C-ratio, emphasizing a high conversion of $\mathrm{CH}_{4}$, the avoidance 
of carbon depositions and a reformate-gases with a sufficient reduction potential. The results suggested that high $\mathrm{CH}_{4}$ conversion of $>99 \%$ is possible, however higher system pressures require a significantly greater $\mathrm{S} / \mathrm{C}$ ratios, and thus yield synthesis gas with increased water content and a lower reduction potential. It was concluded that the reforming in combination with the reduction step of an iron based oxygen carrier should be performed at ambient pressure. The oxidations with steam were executed at elevated pressure up to 8-11 bar to produce hydrogen with a purity $>99 \%$. Small amounts of $\mathrm{CO}_{2}$ were detected, which implied the formation of solid carbon during the reduction, although not predicted by the simulations.

\section{Pressurised oxidations}

Voitic et al. ${ }^{\mathbf{1 0 8 , 1 1 0}}$ analysed the correlations between the increased oxidation pressure and the cycle stability, the conversion efficiency and the structural integrity of an iron based oxygen carrier. Steam oxidations were performed at $750{ }^{\circ} \mathrm{C}$ and at different pressure steps up to 55 bar. The results revealed no repercussion of an increased system pressure on the oxygen carrier conversion and on the oxidation rate. A high purity hydrogen was obtained by pressurized steam oxidation in the range of $99.95-99.999 \%$ with $\mathrm{CO}$ and $\mathrm{CO}_{2}$ as impurities. The amount of carbon impurities was not influenced by the increased system pressure, however a correlation with the length of the reduction reaction was observed. The mass balances indicated an incomplete oxidation of solid carbon by steam. This resulted in an accumulation of solid carbon and a gradually decrease of hydrogen purity. Hence, an air regeneration step had to be included to completely remove carbon contaminations and to regenerate the oxygen carrier. ${ }^{\mathbf{1 0 1 , 1 0 2 , 1 0 8}} \mathrm{A}$ linear decay of the oxygen carrier stability was visible which was related to thermal sintering of iron by deep reduction. A porous structure was maintained in the particles despite the pressure load, which demonstrates the applicability of the chemical looping water splitting process in a fixed bed configuration for high pressure hydrogen production with a hydrocarbon feedstock.

\section{Heavy fraction bio-oil as feedstock}

Zeng et $a l .^{87,97}$ and Xiao et $a .^{58}$ investigated the reduction behaviour of a bio-oil heavy fraction from a cotton stalks pyrolysis unit with a water content of $18.54 \mathrm{wt} \%$. Ilmenite was selected as the proper oxygen carrier in a fixed bed redox reaction for its resistance to carbon depositions and reducibility at temperatures $>950{ }^{\circ} \mathrm{C}$. Preliminary experiments yielded a carbon conversion in the range of $57-82 \%$, which was enhanced by an increasing temperature with an optimum at 950 ${ }^{\circ} \mathrm{C}$. Beyond $950{ }^{\circ} \mathrm{C}$ a declining carbon conversion was measured, which was related to an increased methane crack reaction and the formation of solid carbon. In several consecutive cycles, the ilmenite sample achieved a stable hydrogen yield of 93-96 $\mathrm{Nm}^{3}$ $\mathrm{kg}^{-1}$ within the first 10 cycles. However, after 10 cycles, sever sintering, which led to a lower active surface and average pore diameter, and a drop in released hydrogen was observed. Significant amounts of carbonaceous contaminations were detected with a hydrogen purity below $85 \%$. The gasification of solid carbon with steam was identified as the source of contaminates. The heavy fraction of the used bio-oil contained a high amount of phenolic compounds, thus increasing the tendency towards carbon deposits. In order to improve the hydrogen purity steam was added during the reduction process. A steam/oil ratio of 2.0 improved the carbon conversion of the fuel to $>99 \%$ and enhanced the hydrogen purity to $>99 \%$. However higher amounts of steam decreased the oxygen carrier reduction degree, thus lowering the amount of produced hydrogen.

\section{Hydrothermal hydrogen generation}

Hydrothermal hydrogen generation by the oxidation of iron enables the operation at very mild temperatures in the range of $100-200{ }^{\circ} \mathrm{C}$. This reduces the complexity of the oxidation process significantly compared to conventional chemical looping water splitting, which usually requires temperatures $>600{ }^{\circ} \mathrm{C}$. Feasibly studies were performed by Tsai et al. ${ }^{111}$ in an autoclave by measuring the pressure profile and gas phase at different reactor temperatures. Reference tests were performed with solely water as reactor filling. The supplement of iron powder led to a constant pressure increase, which was further raised by the amount of iron, the reactor temperature and smaller particle sizes. ${ }^{\mathbf{1 1 1}, \mathbf{1 1 2}}$ After oxidizing the iron powder the pressure remained at a constant level. The gas phase consisted of pure hydrogen with a low water content of $0.525 \%$ at $120{ }^{\circ} \mathrm{C}$. Michiels et al. ${ }^{112}$ further enhanced the hydrothermal process by using a 1 molar potassium hydroxide solution. The system was put under $\mathrm{CO}_{2}$ pressure, which dissolved in the aqueous solution and formed potassium carbonate in the presence of potassium hydroxide. The reactor was heated to temperatures up to $200{ }^{\circ} \mathrm{C}$. Iron in the presence of carbonate was oxidized with water to magnetite, $\mathrm{H}_{2}$ and $\mathrm{CO}_{2}$ within a reaction time of 16 h. After cooling down, hydrogen was measured in the gas phase with a purity of $>99 \mathrm{~mol} \%$. Experiments focussing on the role of compressed $\mathrm{CO}_{2}$ in the system revealed that the dissolved carbon dioxide was critical for the process by forming carbonate ions to promote the oxidation of iron to hematite. The absence or deficit of $\mathrm{CO}_{2}$ resulted in a reduced amount of produced hydrogen. An excess of $\mathrm{CO}_{2}$ caused the formation of siderite instead of magnetite, thus a lower amount of hydrogen with significant $\mathrm{CO}_{2}$ contaminations was detected. The presence of potassium hydroxide was vital in the system to promote the solubility of $\mathrm{CO}_{2}$ and the formation of $\mathrm{CO}_{3}{ }^{2-}$-ions. The absence of potassium carbonate resulted in a lower amount of hydrogen. The system did not suffer from a net-carbonate-ions loss within one complete cycle. Hence, the aqueous solution can be reused in the sequential cycle by adding the amount of consumed water.

\section{Process simulations}

The main research focus in the field of chemical looping hydrogen technology is currently on three-reactor systems. These systems are very flexible in terms of the fuel input, while 
maintaining a superior total efficiency compared to conventional hydrogen production processes. Additionally they offer the possibility of a high carbon capture rate with low energy penalties, which makes chemical looping hydrogen systems promising for renewable and fossil feedstocks alike. Particularly emphasising renewable sources, different feedstocks were considered and analysed with regard to their hydrogen production capabilities and system efficiencies. The systems were optimized with the defined specifications of (i) a high solid conversion, (ii) low concentrations of $\mathrm{H}_{2}$ and $\mathrm{CO}$ in the fuel reactor outlet, (iii) no coking, (iv) minimized wt\% of support material, (v) minimized external heat input, (vi) low solid flow rates and (vii) a maximized product gas yield. ${ }^{94}$

\section{Three-reactor chemical looping systems}

Cormos et al. ${ }^{\mathbf{1 1 3 - 1 1 6}}$ evaluated a three-reactor chemical looping system for the co-generation of hydrogen and power using direct coal gasification. Two cases were considered, which differed in their heat integration strategy. Case 1 supplied the required heat in the fuel reactor by the oxidation to $\mathrm{Fe}_{2} \mathrm{O}_{3}$ in the air reactor and case 2 supplied oxygen with an air separation unit (ASU) to the fuel reactor for the partial oxidation of the coal feed. The reduction in the fuel reactor was conducted between $\mathrm{Fe}_{2} \mathrm{O}_{3} / \mathrm{FeO}$ at 38 bar and $650-900{ }^{\circ} \mathrm{C}$ and produced a pure $\mathrm{CO}_{2}$ stream for carbon capturing. Hydrogen released in the steam reactor was consumed in a gas turbine for power generation or compressed to 60 bar for a hydrogen infrastructure. Results focusing solely on power generation yielded a net electrical efficiency in the range of $41-42 \%$ for both cases with a carbon capture rate of $>99 \%$. The two benchmark systems, a conventional IGCC with Selexol pre-combustion capture and an IGCC with an upstream shell gasifier and a downstream TRCL system yielded a slightly lower efficiency of $37.11 \%$ and $38.38 \%$ respectively. The IGCC chemical looping system enabled a carbon capture rate $>99 \%$ whereas the conventional coal gasification facilitated a carbon capture rate of roughly $91 \%$. The net efficiency of case 1 was further improved to $49.88 \%$ by increasing the hydrogen output to approximately $50 \%$ of the overall power output. Mukherjee et al. ${ }^{117}$ analysed a coal gasification power plant in the range of $400 \mathrm{MW}$ using three-reactor chemical looping for electricity and hydrogen generation. In the operation focusing on gas yields, with a hydrogen power output share of $78 \%$, a total plant efficiency of $59.4 \%$ and an exergy efficiency of $53.0 \%$ was possible, while maintaining a $\mathrm{CO}_{2}$ capturing efficiency of $99 \%$. Two benchmarks systems based on IGCC with PSA or Selexol for carbon capturing yielded similar energy and exergy efficiencies, however at the cost of lower $\mathrm{CO}_{2}$ capturing efficiencies of $89.9 \%$ and $93.5 \%$ respectively. Similar advantages were reported when comparing the iron-based looping systems to calcium-based looping systems. Two calcium based systems with either a pre- or a post-combustion design inhered lower net efficiencies of $4-6 \%$ points with a carbon capture rate of approximately $96 \% .{ }^{\mathbf{1 1 6}}$

Sorgenfrei et $a .^{86}$ analysed an IGCC-chemical looping hydrogen system using either a shell gasifier or a British Gas/ Lurgi (BGL) oxygen-blown moving-bed gasifier. Bituminous coal was selected as feed and iron oxide served as the oxygen carrier. Both systems outperformed conventional IGGC systems in terms of net efficiency in the range of $38.1-41.4 \%$ and in terms of carbon capturing efficiency. The comparison of the two chemical looping systems indicated an advantage of the BGL gasifier over the shell gasifier regarding efficiency and design simplicity. The BGL systems required less oxygen for the gasification, thus consuming less power in the air separation unit (ASU). However, the chemical looping cycle in the BGL systems required an increased solid flow to convert the synthesis gas completely, and therefore a higher airflow to oxidize the oxygen carrier. The air reactor temperature was identified as a critical parameter for efficiency optimization. An increase of the temperature from 800 to $1000{ }^{\circ} \mathrm{C}$ resulted in a reduced solid mass flow and a decreased power consumption, thus raising the efficiency by $4.6 \%$ points. The addition of a $\mathrm{CO}_{2}$ turbine reduced the total system efficiency despite the $60 \%$ surplus generation of electrical energy because of its repercussions on the heat recovery in the steam cycle.

Yang et al. ${ }^{118}$ integrated a three-reactor system into a Fushuntype oil shale retorting process (OSR-CLH) (Fig. 11). In conventional oil shale plants, a retorting gas with a low heating value is produced and converted to electricity via an internal combustion engine. The chemical loop process instead utilizes this retorting gas for hydrogen production. The process heat provided by the off-gas from the three reactors was used for power generation. The oil-retorting reactor was operated at 520 ${ }^{\circ} \mathrm{C}$ to maximize the hydrogen and shale oil yield. The $\mathrm{Fe}_{2} \mathrm{O}_{3}$ solid flow rate was adjusted to enable a complete conversion of the retorting gas to $\mathrm{H}_{2} \mathrm{O}$ and $\mathrm{CO}_{2}$ and the steam flow was regulated to fully re-oxidize the iron based oxygen carrier. An exergy comparison and techno-economic analysis was performed between the conventional plant and the OSR-CLH system in a realistic production scale of $375 \mathrm{t} \mathrm{h}^{-1}$ oil shale.

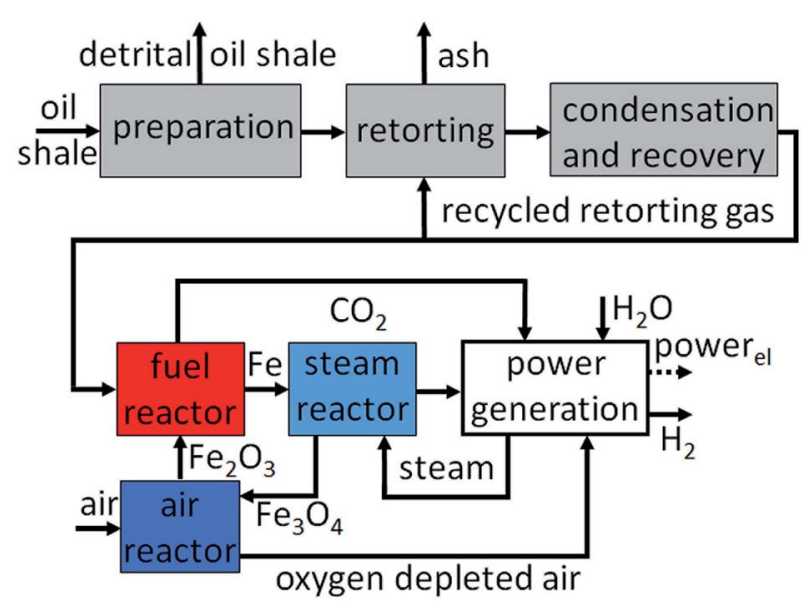

Fig. 11 Process diagram of the combination of an oil shale retorting process with a chemical looping hydrogen process by Yang et al. ${ }^{118}$ Reprinted and adapted with permission from Q. Yang, Y. Qian, Y. Wang, $\mathrm{H}$. Zhou, and S. Yang, Development of an oil Shale retorting process integrated with chemical looping for hydrogen production, Ind. Eng. Chem. Res., 2015, 54, 6156-6164, Copyright (2015), American Chemical Society. 
The conventional plant suffered from a larger exergy destruction within the combustion engine, meaning that the OSR-CLH system had a higher total plant efficiency of $7.3 \%$ points. However, the economic analysis indicated higher capital costs and higher production costs for the chemical looping system of approximately $23 \%$ caused by the additional system units and by the oxygen carrier as second material.

Zeng et al. ${ }^{119}$ simulated a direct coal three-reactor chemical looping plant solely for hydrogen generation using iron oxide. The fuel reactor temperature was operated at $900{ }^{\circ} \mathrm{C}$ with a solid conversion of $56.3 \%$. Two pressure conditions $30 \mathrm{~atm}$ and $2 \mathrm{~atm}$ with $\mathrm{Fe}_{2} \mathrm{O}_{3} /$ coal flow rate ratio of 1.38 enabled a complete coal conversion. A pressure increase beyond 30 atm reduced the coal conversion efficiency. In the steam reactor, a temperature of 700 ${ }^{\circ} \mathrm{C}$ and a steam/Fe ratio of 1.9 ensured a complete oxidation to magnetite while optimizing the steam conversion irrespective of the selected system pressure. The two operation conditions, pressurized and atmospheric, yielded total efficiencies of $79.69 \%$ and $71.36 \%$ respectively with carbon capture rates of 99\%. The operation at atmospheric pressure had a lower efficiency, however, the absence of gas compressors and expanders significantly lowered the plant investment cost and its complexity. A third case, which considered kinetical limitations with a lower carbon conversion of $95 \%$ yielded a total efficiency of $77.24 \%$. The lower coal conversion led to carbon impurities in the produced hydrogen. Hence, a higher purification effort and a larger amount of tail-gas had to be taken into account. The formation of pollutants, which originated from the coal feed were considered. Chlorine was converted to $\mathrm{HCl}$, whereas mercury stayed in elemental form in the fuel reactor. Both pollutants exited the system with the $\mathrm{CO}_{2}$ stream. Sulphur formed $\mathrm{Fe}_{0.877} \mathrm{~S}$ in the reducer and was mainly carried over to the steam and air reactor where it was re-oxidized, resulting in both $\mathrm{H}_{2} \mathrm{~S}$ and $\mathrm{SO}_{2}$ being present in the system.

Chen et al. ${ }^{\mathbf{1 2 0}}$ simulated the integration of a three-reactor chemical looping hydrogen system with a SOFC/gas turbine system for power generation. A shell gasifier was selected to convert bituminous coal to a synthesis gas. The reduction gas was utilized to convert an iron based oxygen carrier to wustite at $950{ }^{\circ} \mathrm{C}$ in the fuel reactor. Pure hydrogen was generated in the steam reactor at $750-800{ }^{\circ} \mathrm{C}$ and supplied to a SOFC. The SOFC anode off gas, which contained $10-25 \%$ of hydrogen, was burned in a gas turbine. Heat recovery steam generator systems were installed downstream after the fuel reactor and the gas turbine. The combination of a CLH system with a SOFC and the utilization of pure hydrogen was expected to show advantages regarding (i) better electrochemical kinetics, (ii) the complete prevention of solid carbon formation, (iii) a better heat distribution by avoiding endothermic reforming reactions and (iv) the complete sequestration of carbon from the fuel. The plant analysis yielded an electrical efficiency of $43.53 \%$ with complete $\mathrm{CO}_{2}$ sequestration. A higher system pressure was found to be beneficial for raising the total efficiency, while increasing reaction temperatures in the chemical looping plant had only limited effects on the overall plant efficiency. The variation of the steam reactor temperature raised the power output of the gas turbine but lowered the power output of the steam turbine, hence the two effects annulled each other. The analysis of the three-reactor chemical looping hydrogen system combined with a SOFC by Ozcan et al. ${ }^{121}$ yielded a total energy efficiency of $45.39 \%$ for full power conversion and $56.92 \%$ for combined power/hydrogen production (ratio of 1.5/1). The two cases resulted in total exergy efficiencies of $34.98 \%$ and $45.05 \%$ respectively. The three-reactor chemical looping components alone contained an energy and exergy efficiency of $65.37 \%$ and $57.9 \%$ respectively. The highest amount of exergy destruction occurred in these elements due to the high process heat and the low hydrogen yield. Operating conditions required to maintain a complete conversion of syngas and the full re-oxidation of $\mathrm{Fe} /$ $\mathrm{FeO}$ to $\mathrm{Fe}_{3} \mathrm{O}_{4}$ were determined. Hence, the ratio of steam to feed played a substantial role in terms of efficiency. Another important parameter was the ratio of utilized/stored hydrogen. The system efficiency was raised by roughly $10 \%$ points by increasing the amount of deliverable hydrogen to $40 \%$ of the total power output at the cost of electric efficiency. ${ }^{116,119,121}$

\section{Two-reactor chemical looping systems}

Chen et $a{ }^{90}{ }^{90}$ combined an iron oxide based two-reactor cyclic water-splitting system with a nickel oxide based chemical looping combustion unit. Syngas, produced by coal gasification in a shell gasifier, was used as a feed. The oxygen carrier was cycled between magnetite and wustite, thus syngas was not fully converted in the Fe fuel reactor. This lean gas reduced the nickel oxide in a second fuel reactor. The Ni-looping cycle was closed by oxidation with air. A pure hydrogen stream was generated in the iron cycle, while the nickel cycle yielded a pure carbon dioxide stream. Both streams were expanded separately for power generation and heat recovery. Two cases were investigated, the first using a supplementary firing unit to increase the turbine inlet temperature of the oxygen deplete air gas stream. Hence, carbon emissions were produced with a carbon capture efficiency of $69.54 \%$. The second cases omitted the supplementary firing unit and enabled a complete carbon sequestration. The total equivalent efficiency for both cases were $70.75 \%$ and $57.9 \%$ respectively. Operation parameters were varied to optimize the electrical power efficiency and the hydrogen yield for co-generation. A flexible production ratio of hydrogen and electricity was achieved by varying the iron oxide solid flow rate. The hydrogen production efficiency was optimized by raising the steam flow and the temperatures in the steam reactor and air-reactor. The addition of an inert support to the nickel oxide improved the heat integration in the system and the hydrogen efficiency. Generally, a trade-off between hydrogen production efficiency and total efficiency was visible, hence a raised hydrogen yield was accompanied by a reduction in power efficiency. Both efficiencies were elevated with higher iron fuel reactor temperatures but at the cost of dropping carbon capture rates.

\section{Evaluation of operation parameter}

Kathe et al. ${ }^{94}$ analysed $\mathrm{CH}_{4}$ as fuel in a three-reactor chemical looping hydrogen system using an iron oxide as oxygen carrier supported by $\mathrm{Al}_{2} \mathrm{O}_{3}$. Sensitivity analyses were executed to 
maximize the hydrogen production efficiency. Initial thermodynamic simulations explained the benefits of a countercurrent moving bed of reactants and solid material compared to a co-current fluidized system. This operation mode reached the thermodynamic constraints of redox cycling more efficiently, thus lowering the required steam/solid ratio to reach a defined solid conversion. Additionally, a higher fuel/solid ratio was possible, while maintaining a complete fuel conversion. An increase of support material increased the reactor outlet temperature and the solid conversion at a fixed solid/ $\mathrm{CH}_{4}$ ratio, which enabled a full conversion of methane without the risk of coking. A value of $50 \mathrm{wt} \% \mathrm{Al}_{2} \mathrm{O}_{3}$ was found to be optimum. The sensitivity analysis of Kang et al. ${ }^{122}$ based on a linear empirical kinetic model suggested a content of $20 \mathrm{wt} \%$ of $\mathrm{Fe}_{2} \mathrm{O}_{3}$ on $\mathrm{ZrO}_{2}$ as suitable content. The reaction temperatures in the steam and fuel reactor reactors were key to minimize the bed material input. In both reactors, an increase in the temperature reduced the required solid inventory to an optimum temperature value. Beyond the optimum, a contrary behaviour was observed in the steam reactor, which was related to the exothermic nature of the reaction and the unfavourable equilibrium. Khan et al. ${ }^{123}$ reported an increasing $\mathrm{CO}_{2}$ and $\mathrm{H}_{2}$ yield by raising the flow rates of steam, fuel and air until the stoichiometric values were reached. A Fe-oxygen carrier with 70 wt $\% \mathrm{MgAl}_{2} \mathrm{O}_{4}$ as support yielded the highest amounts of product gases, whereas higher values reduced the gas output. Higher solid mass flow rates enabled an enhanced $\mathrm{H}_{2}$ and $\mathrm{CO}_{2}$ yield until an optimum. Kathe et al. ${ }^{94}$ analysed the steam conversion and outlet temperature, based on the oxygen carrier composition by adjusting the steam/solid ratio, steam conversion and outlet temperature. A re-oxidation to $11 \%$ of solid conversion yielded the highest amount of heat released at a high steam conversion efficiency. To complete the looping cycle, re-oxidation with air and a split of the solid flow was used, which bypasses the steam reactor and is directly transferred to the air reactor. The operation parameter air flow/fuel and split ratio of solid to oxidizer/bypassing-oxidizer were specified to facilitate auto-thermal operation conditions. The final plant layout for the simulation used a solid stream split of 0.15 , which bypassed the steam reactor and was directly fed into the air reactor. In addition, $9 \%$ of the natural gas feed was directly injected into the air reactor in order to deliver the required heat duty. Hence, the process enabled a carbon capture rate of only $90 \%$. A hydrogen production rate of $25711 \mathrm{~kg} \mathrm{~h}^{-1}$, while utilizing $6196 \mathrm{~kg} \mathrm{~h}^{-1}$ natural gas and a solid conversion of $60 \%$, was calculated and utilized in several case studies. The highest system efficiencies were obtained by performing the process at a system pressure of $10 \mathrm{~atm}$ and exploiting a comprehensive energy recovery, which included gas expanders and a heat recovery steam generation system (HRSG). A cold gas efficiency of $77.6 \%$ and a thermal efficiency of $75.1 \%$ was obtained compared to $72.1 \%$ and $69.7 \%$ of the reference case (a conventional SMR system). The chemical lopping system required $8 \%$ less natural gas and had a lower cooling demand and water requirement than the SMR case. Sanfilippo et al. ${ }^{85}$ reported that an increase in the solid circulation rate required an external electric power input, but could further enhance the hydrogen production capacity and increase the total efficiency. The simulation results indicated a total system efficiency in the range of $78-79 \%$, while maintaining a full carbon capture rate. The system variation can alter the process design and capabilities significantly. For instance, an increase in thermal efficiency was obtained by reducing carbon capture capabilities, while omitting the heat recovery units and lowering the operation pressure reduced the system complexity and the capital system costs at the expense of a lower thermal efficiency. ${ }^{116}$

Zhang et al. ${ }^{124,125}$ performed thermodynamic and exergetic analyses on a two-reactor chemical looping hydrogen system and different oxygen carriers using methane as feed. The hydrogen produced in the steam reactor was burned with pure oxygen from an air separation unit. The generated steam was used for power generation in a steam turbine. The residual heat after the turbine is re-fed to supply the endothermic reaction in the fuel reactor. In a second system, the power generation unit consisted of a high-pressure and a low-pressure steam turbine. The single turbine and double turbine systems yielded a thermal efficiency of $55.5 \%$ and $59.8 \%$ respectively, which were $0.9 \%$ and $5.2 \%$ points higher than conventional combined cycles. The authors assumed a carbon capturing without any additional energy penalties by generation of a stream of $\mathrm{CO}_{2}$ and $\mathrm{H}_{2} \mathrm{O}$ and by the reduction between $\mathrm{Fe}_{3} \mathrm{O}_{4}$ and $\mathrm{FeO}$ in the fuel reactor. Hence, the efficiency was further raised by $7-9 \%$ points. The work does not discuss how the pure outlet stream in the fuel reactor is produced by the reduction of magnetite with $\mathrm{CH}_{4}$. The two reactor chemical looping system was integrated into a coal based methanol production system. ${ }^{126}$ Heat from the coal gasification, which supplied syngas for the methanol synthesis, was used in the chemical looping system for hydrogen supply. The reduction in the looping fuel reactor was performed with natural gas. The exergy analysis indicated that utilizing the coal gasification heat reduced the exergy destruction compared to the conventional operation of combusting parts of the natural gas. Metals suitable for use as oxygen carrier such as $\mathrm{Ni}, \mathrm{Zn}$ and $\mathrm{Fe}$ enable a steam oxidation at low equilibrium temperatures and thus assist in the conversion of chemical energy with very high second law efficiency. Energy savings are made possible by minimizing the exergy destruction and the lowered consumption of natural gas..$^{18,125,126}$

\section{Unconventional feedstocks}

Cormos et al. ${ }^{127}$ investigated the replacement of coal with biomass (sawdust) as feedstock. The external gasifier still required a high amount of coal $(70 \%)$ in the feed because the commercial availability of industrial scale gasifier solely for biomass is limited. The iron based chemical looping systems achieved the highest electric efficiency and a carbon capture rate $>99 \%$ with the lowest carbon capture energy penalty. The reference systems based on gas liquid absorption achieved an energy efficiency $5.7 \%$ points lower than the chemical looping plant. Yan et al. ${ }^{128}$ added a SOFC unit to the biomass-fed threereactor chemical looping hydrogen system using coal and wheat straw. Post combustion of the anode off-gas, a steam turbine for power generation and $\mathrm{CO}_{2}$ sequestration were considered. The 
amount of hydrogen and the total thermal efficiency were raised by increasing the gasification temperature, which improved the carbon conversions efficiency. Upon reaching a complete biomass conversion no further positive temperature effects were visible. The same behaviour was found regarding the S/C ratio in the gasification unit. Below the ratio for a complete biomass conversion an increased amount of steam indicated positive effects on the plant performance, while an excess of steam lowered the total efficiency. The increased oxygen carrier circulation rate raised the amount of produced hydrogen per mass biomass. However, upon reaching the point of full oxidation of $\mathrm{CO}$ to $\mathrm{CO}_{2}$, only hydrogen was consumed for the reduction reaction in the fuel reactor, which lowered the plant performance. The system evaluation yielded a total energy efficiency of $39.9 \%$ and total exergy efficiency of $37.6 \%$ with a carbon capture rate of $96 \%$. The comparison of a three-reactor system and a two-reactor system using the same feed gas conveyed the main difference in the behaviour of the fuel reactor temperature. ${ }^{129}$ Higher temperatures in a three-reactor system increased both the total thermal efficiency as well as the amount of hydrogen per mass feed. The endothermic reduction reaction was thermodynamically promoted at higher temperatures and enabled a greater reduction degree of the oxygen carrier. In the two-reactor system the lack of an air oxidation to meet the required heat supply had to be substituted by combustion of biomass. Thus the thermal efficiency and the amount of hydrogen per mass feed decreased. Both systems enabled a carbon capture rate of $>95 \%$. The two-reactor system had a higher cold gas efficiency of $60 \%$ compared to $54 \%$ and a higher hydrogen production capability of $0.76 \mathrm{Nm}^{3} \mathrm{~kg}^{-1}$ compared to $0.66 \mathrm{Nm}^{3} \mathrm{~kg}^{-1}$. A calcium based sorption enhanced looping system used as reference had a higher cold gas efficiency of $72 \%$ with $0.73 \mathrm{Nm}^{3} \mathrm{~kg}^{-1}$ of hydrogen but a lower carbon capture efficiency of $92 \%$.

The application of bioethanol (12\% ethanol and $88 \%$ water) from fermentation processes was examined by Cormos. ${ }^{130}$ High system efficiencies were achieved in two system variations, (i) an upstream reforming reactor with a syngas based chemical looping and (ii) a direct bioethanol chemical looping system. The total energy efficiencies were $59.78 \%$ with an electric power output of $13 \%$ and $63.66 \%$ with an electric power output of $7 \%$. The carbon capture rate was $>99 \%$ in both plant simulations. The conventional reforming system with a gas-liquid absorption as a benchmark yielded efficiencies in the range of $53-58 \%$, while enabling a carbon capture efficiency of $>99 \%$.

Gopaul et al. ${ }^{\mathbf{1 3 1}}$ investigated the conversation of unconventional biomass. Three types of biomass were evaluated, assuming the absence of sulphur and nitrogen components. Poultry litter was chosen over wood pellets and oak pellets because of the higher hydrogen yield. Tar products formed during the biomass gasification process were not separated but fed into the chemical looping fuel reactor. Reduced iron and remaining tars were separated from the gaseous products and fully oxidized in the steam reactor. Both reactors yielded a hydrogen rich synthesis gas $\left(\mathrm{H}_{2}, \mathrm{CO}_{2}, \mathrm{CO}, \mathrm{CH}_{4}, \mathrm{H}_{2} \mathrm{O}\right)$, which was utilized in a reformer at $500{ }^{\circ} \mathrm{C}$ to oxidize the residual methane and maximize the hydrogen output. A hydrogen yield of $1.60 \mathrm{kmol} \mathrm{kmol}_{\text {feed }}{ }^{-1}$ diluted with $34 \% \mathrm{CO}_{2}$ and $2.3 \% \mathrm{H}_{2} \mathrm{O}$ with a final hydrogen purity of $63 \%$ was obtained. A reference water-gas-shift system generated $0.97 \mathrm{kmol} \mathrm{kmol}_{\text {feed }}{ }^{-1}$. Sanz et $a l .{ }^{132}$ calculated the hydrogen production cost using a tworeactor chemical looping system. A syngas stream with a mass flow of $27820 \mathrm{~kg} \mathrm{~h}^{-1}$ produced by biomass gasification was assumed as feed. The feed stream contained high amounts of steam and a low reducing potential, thus the stream was cooleddown to condense the water before entering the fuel reactor. Two reactors were assumed in reduction mode per each reactor in oxidation mode, with a total of 12 reactors for handling the used feed stream. The system calculations were based on thermodynamic considerations of the Baur-Glaessner diagram. The reduction off gas was burned to provide heat for the system. Under the consideration of equipment costs, amortization and operation costs a hydrogen production of $4786 \mathrm{t}$ per year with production costs of $2.13 € \mathrm{~kg}^{-1}$ hydrogen were obtained. Comparative data based on a conventional water-gas-shift system resulted in production costs of $1.76 € \mathrm{~kg}^{-1}$. The techno-economic evaluation indicated higher investment, operation and maintenance costs (O\&M) for chemical looping hydrogen systems compared to state-of-the art technology. The high degree of technological complexity and the small number of large-scale applications are the two main cost factors. However, under the consideration of costs per energy output the direct biomass chemical looping system has the lowest costs due to the high system efficiency and low carbon capture energy penalty. ${ }^{127,132}$

Edrisi et al. ${ }^{\mathbf{8 3 , 1 3 3}}$ proposed a three-reactor chemical looping technology to produce pure streams of hydrogen and nitrogen as feed for an ammonia production plant and a third stream of pure carbon dioxide for sequestration. In the fuel reactor an iron based oxygen carrier completely converted $\mathrm{CH}_{4}$ to $\mathrm{CO}_{2}$ at $726{ }^{\circ} \mathrm{C}$. In the steam reactor a pure hydrogen stream was produced by partially oxidizing iron with steam at $723^{\circ} \mathrm{C}$. In the air reactor, a pure nitrogen stream was generated at $880^{\circ} \mathrm{C}$ by fully consuming oxygen in the air stream and completely oxidizing the solid material. The fuel and air fed and the oxygen carrier fed were varied to optimize the operation conditions with regard to the product streams. The ratio $\mathrm{OC} / \mathrm{CH}_{4}$ of 4.0 and the ratio air/ $\mathrm{CH}_{4}$ of 3.206 were found to enable the production of pure streams, while maximizing the reduction degree of the solid material. $\mathrm{MgAl}_{2} \mathrm{O}_{4}$ was added as support material with a ratio of $\mathrm{MgAl}_{2} \mathrm{O}_{4} / \mathrm{CH}_{4}$ of 6 to improve the heat integration of the system. ${ }^{\mathbf{1 3 3}}$ The simulation yielded a hydrogen production efficiency of $80.2 \% .^{133}$

\section{Kinetic studies}

Several papers have been published on the kinetic characterization of the reduction and oxidation of iron based oxygen carriers. Besides pure iron oxygen, supported samples and the interactions between the active components and the supporting components were studied. The kinetic data and redox models gained is important information for modelling large-scale chemical looping plants and process optimizations. The presented data is summarized in Table 3. 
के के ले के अ

$\exists$

안

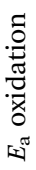

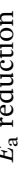

정

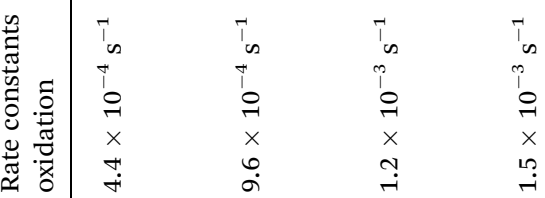

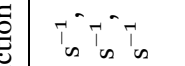

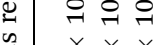

$\begin{array}{lll}x & x \\ \infty & + & x \\ 1 & + & 1\end{array}$

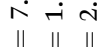

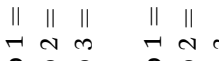

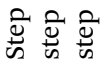

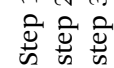

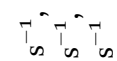

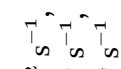

응응

$\times \times \times \times x$

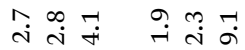

$\begin{array}{llll}\| & \| & \| & \|\end{array} \|$

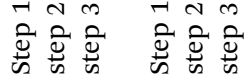

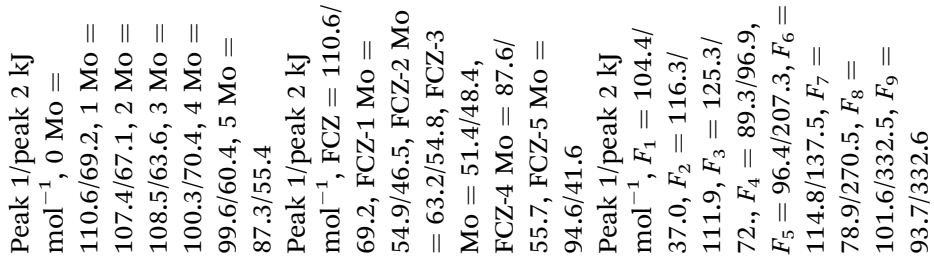

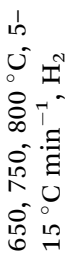

$T_{0}^{2}$

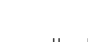

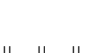

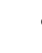

苛

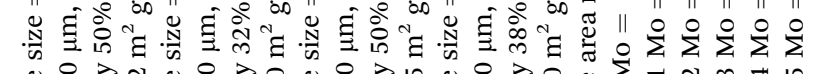

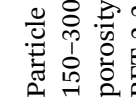

节

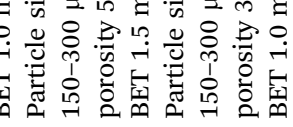

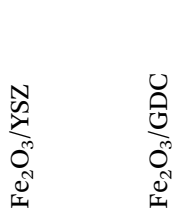

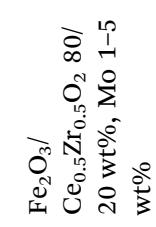

क
1
1
0
0
0
0
0
0
0

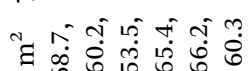

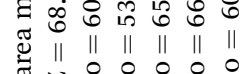

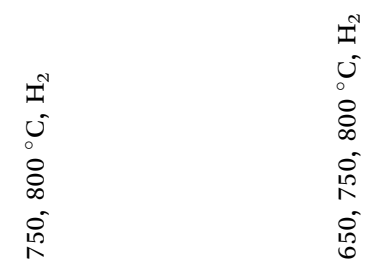

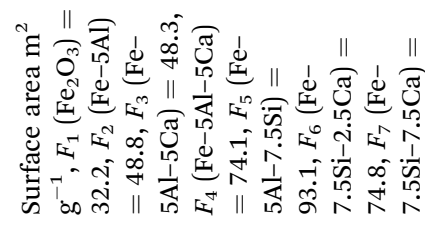

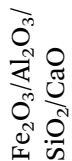




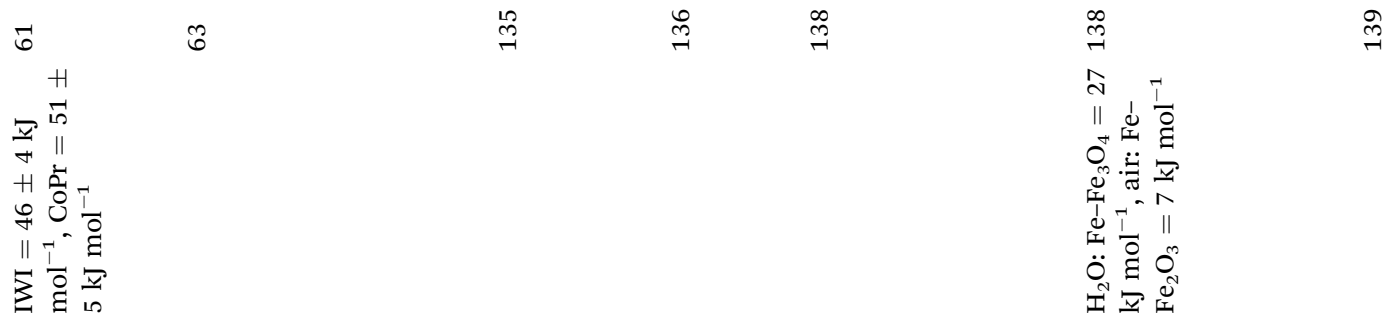

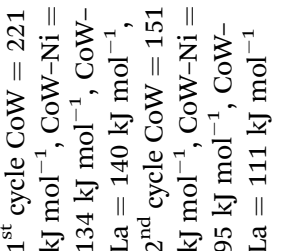

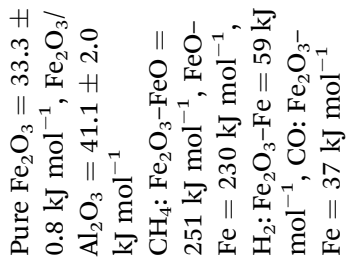

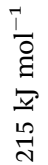

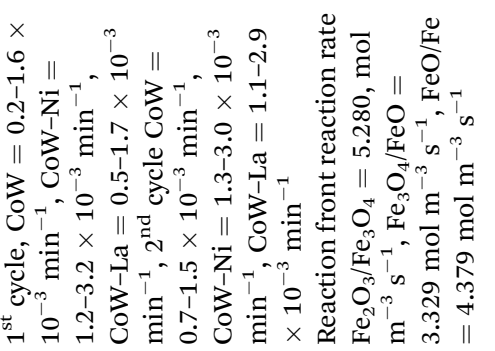

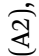

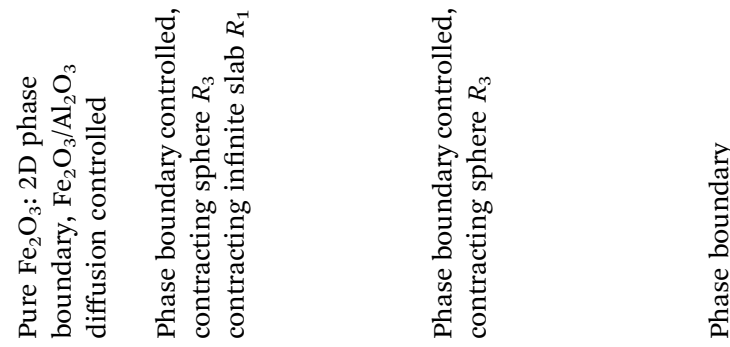

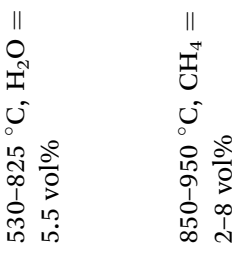

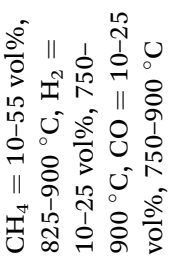

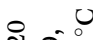

氜
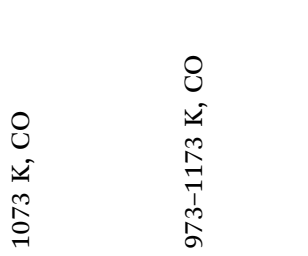

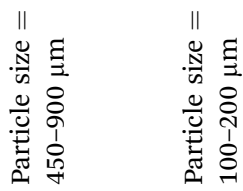

की

के

这薃

范

至

मी

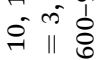

เิ

0 월

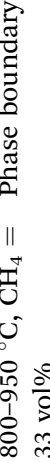

造 $\frac{1}{4}$

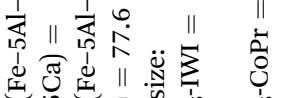

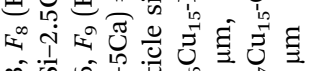

कํ.

\section{要}

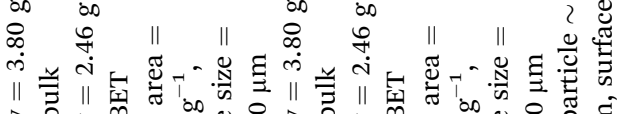

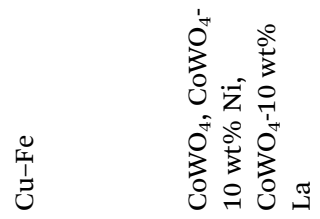

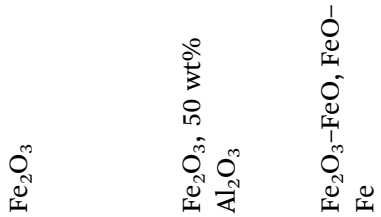

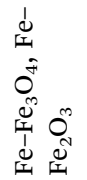

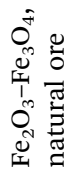




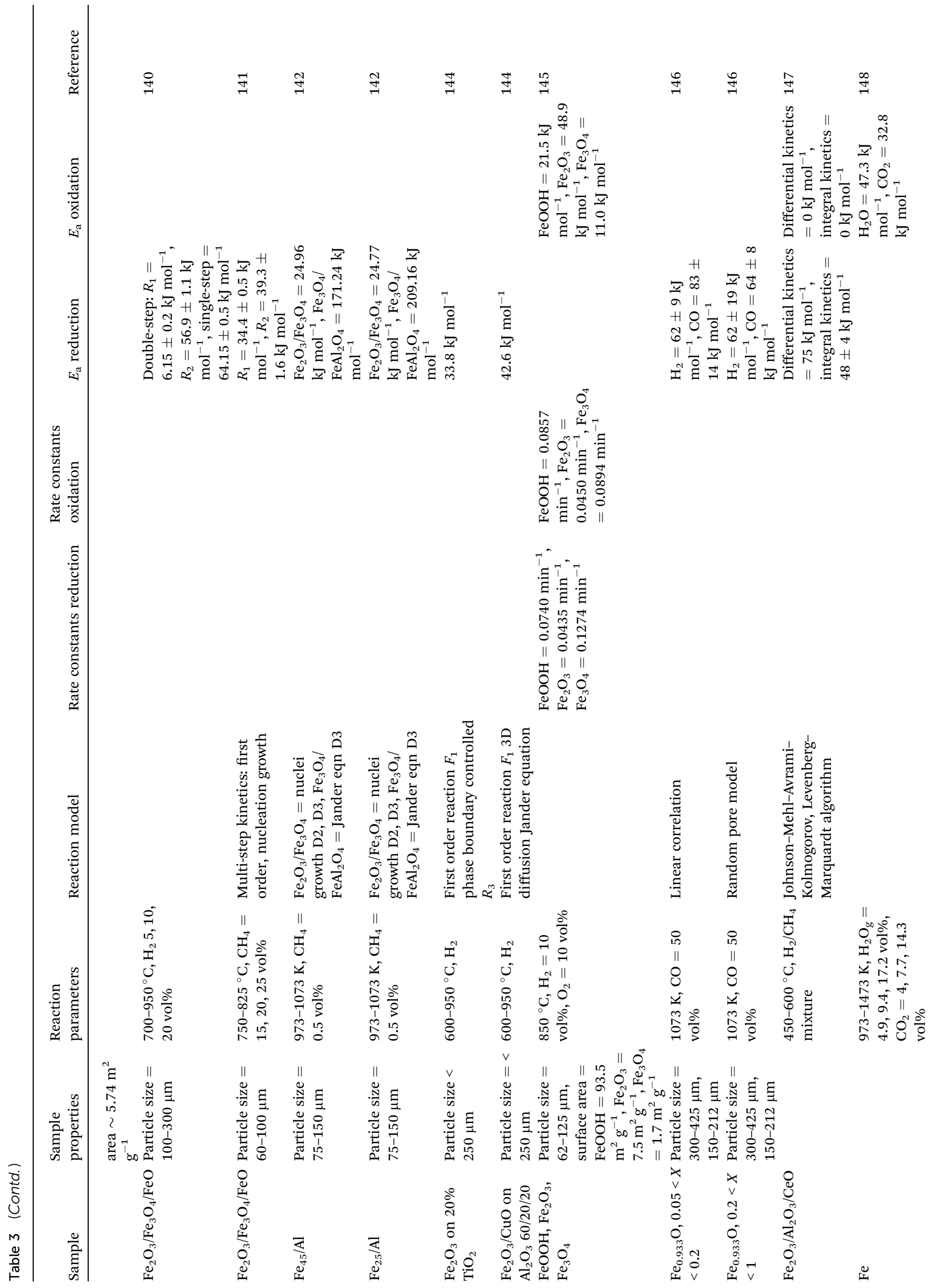


Zhu and Hua et $a .^{\mathbf{1 3 4 - 1 3 6}}$ analysed the reduction stage distribution in a fixed bed reactor under fuel breakthrough operation. Reductions were performed at $900{ }^{\circ} \mathrm{C}$ with a mixture of $\mathrm{CO}$ and $\mathrm{CO}_{2}$ in a tubular reactor divided into 10 separated segments by quartz cotton. The oxygen carrier analyses indicated an uneven solid conversion caused by the reaction front with their different reduction kinetics moving through the reactor (Fig. 12). The first two layers contained $\mathrm{Fe}$ and $\mathrm{FeO}$ with a mass percentage of $85 \mathrm{wt} \%$ and $7 \mathrm{wt} \%$ respectively, while $\mathrm{FeO}$ and $\mathrm{Fe}_{3} \mathrm{O}_{4}$ were found in the remaining 8 layers. In the consecutive steam oxidation the segments 1-6 contributed to $90 \%$ of the produced hydrogen. Hertel et al. ${ }^{137}$ identified the two zones with a stable conversion which corresponded to the reduction zones of $\mathrm{Fe}_{3} \mathrm{O}_{4} / \mathrm{FeO}$ and $\mathrm{FeO} / \mathrm{Fe}$ described by the Baur-Glaessner diagram. Stable zones were separated by transition periods, which are induced by limited gas-solid reaction rates. The simulation results indicated that the travel time of the reaction zones is 3-4 orders of magnitude of the gas phase movement. Zhu et al. ${ }^{\mathbf{1 3 4}}$ separated each reduction step by adapting the $\mathrm{CO} / \mathrm{CO}_{2}$ feed-ratio according to the phase equilibrium. The reaction rates of the reductions $\mathrm{Fe}_{2} \mathrm{O}_{3} / \mathrm{Fe}_{3} \mathrm{O}_{4}$ and $\mathrm{FeO} / \mathrm{Fe}$ possessed similar characteristics with a rapid increase to a stable maximum. Both steps ended with a fast decline until the conversion rate dropped. $\mathrm{Fe}_{2} \mathrm{O}_{3}$ was completely reduced, while $36 \%$ of $\mathrm{FeO}$ remained unreacted after step 3 . The second step $\mathrm{Fe}_{3} \mathrm{O}_{4} / \mathrm{FeO}$ had the slowest reduction rate, approximately one order of magnitude lower than the other two, with a continuous linear decrease and a reaction stop at a solid conversion of roughly $38 \%$, meaning that it should be the focus of material optimization. The reaction front velocities were in the order $\mathrm{Fe}_{2} \mathrm{O}_{3} / \mathrm{Fe}_{3} \mathrm{O}_{4}>\mathrm{FeO} / \mathrm{Fe}>\mathrm{Fe}_{3} \mathrm{O}_{4} / \mathrm{FeO}$. Reduction simulations of $\mathrm{Fe}_{2} \mathrm{O}_{3}$ with $\mathrm{CO}$ in a temperature range of 973-1173 K were executed with the phase boundary kinetic model. ${ }^{\mathbf{1 3 6}}$ However, the addition of $50 \mathrm{wt} \% \mathrm{Al}_{2} \mathrm{O}_{3}$ revealed a transition from a phase boundary to a diffusion controlled kinetic model to better match the experimental results. An explanation was provided by SEM analysis. Larger pores were found in the reduced pure sample, whereas the supported oxygen carrier

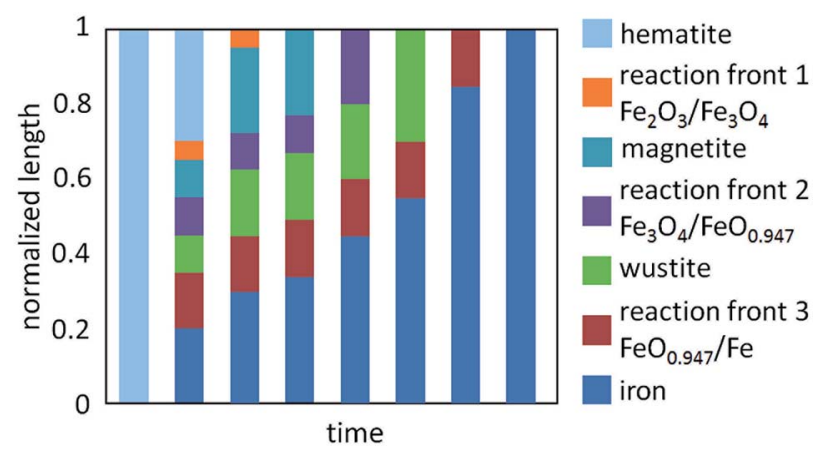

Fig. 12 Schematic temporal progression of the reaction fronts in a fixed bed at $800{ }^{\circ} \mathrm{C} .135$ Reprinted and adapted with permission from $X$. Hua, W. Wang, and Y. Hu, Analysis of reduction stage of chemical looping packed bed reactor based on the reaction front distribution, $J$. Mater. Cycles Waste Manag., 2014, 16, 583-590, Copyright (2014), Springer Japan. possessed grain clusters with reduced porosity, which are expected to hamper the gas diffusion. Kang et al. ${ }^{138}$ performed an extensive isothermal kinetic investigation on iron oxide supported with $80 \mathrm{wt} \% \mathrm{ZrO}_{2}$ at temperatures of $740-900{ }^{\circ} \mathrm{C}$. The reduction with methane was separated into two steps $\mathrm{Fe}_{2} \mathrm{O}_{3} \rightarrow$ $\mathrm{FeO}$ and $\mathrm{FeO} \rightarrow \mathrm{Fe}$, while the reduction with $\mathrm{H}_{2}$ and $\mathrm{CO}$ was considered a one-stage reaction. According to the Hancock and Sharp method the phase-boundary controlled mechanism was suitable for describing all reduction and oxidation reactions except the second step of the methane reduction, which showed a linear behaviour. Nasr et al. ${ }^{139}$ studied the reduction kinetic of a natural iron ore with $\mathrm{CH}_{4}$. Reactions were performed in a TGA in the temperature range of $800-950{ }^{\circ} \mathrm{C}$. Based on the Hancock and Sharp method, a phase boundary controlled mechanism was used to describe the solid conversion. The impurities in the natural ore, mainly $\mathrm{SiO}_{2}, \mathrm{CaO}, \mathrm{MgO}$ and $\mathrm{Al}_{2} \mathrm{O}_{3}$ were expected to lower the activation energy which resulted in a value of $215 \mathrm{~kJ}$ $\mathrm{mol}^{-1}$ for the reduction reaction.

Monazam et al. ${ }^{\mathbf{1 4 0}}$ analysed the reduction kinetics of hematite particles to wustite with $20 \%$ hydrogen in a thermogravimetric analysis system (Fig. 13). Changing values were obtained for the activation energies, depending on the solid conversion initially decreased from 23 to $8 \mathrm{~kJ} \mathrm{~mol}^{-1}(0.025<$ solid conversion $<0.1)$ followed by an increase to $47 \mathrm{~kJ} \mathrm{~mol}^{-1}(0.1<$ solid conversion $<0.33)$ and finally declined to $30 \mathrm{~kJ} \mathrm{~mol}^{-1}(0.33<$ solid conversion $<1$ ), suggesting a double-step reduction kinetic. In a temperature range of $700-800{ }^{\circ} \mathrm{C}$ a $1 \mathrm{D}$ nucleation growth model including an induction period was used to describe the reaction process. At temperatures beyond $900{ }^{\circ} \mathrm{C}$ the induction period diminished and the single-step nuclei growth reaction became dominant. A similar approach was used for the reduction kinetics of hematite with $\mathrm{CH}_{4}$ (15-35 vol\%). ${ }^{141}$ However, the kinetic models did not properly describe the reaction. The analysis of the activation energy corresponding to the solid reduction degree indicated a descending trend from 56 to $36 \mathrm{~kJ} \mathrm{~mol}^{-1}$ with the conversion progressing from 0.1 to 0.5 . Hence, a multi-step parallel model with a superposition of a first order reaction and a nucleation model was applied. Activation energies for the two reaction steps of $34.4 \pm 0.5 \mathrm{~kJ}$ $\mathrm{mol}^{-1}$ and $39.3 \pm 1.6 \mathrm{~kJ} \mathrm{~mol}^{-1}$ were obtained. Zhang et al. ${ }^{\mathbf{1 4 2 , 1 4 3}}$

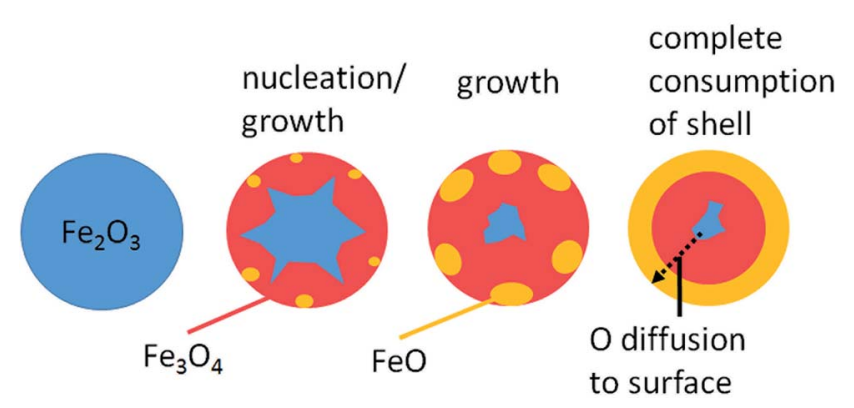

Fig. 13 Schematic representation of the progression of the reduction of $\mathrm{Fe}_{2} \mathrm{O}_{3}$ to $\mathrm{FeO} .{ }^{140}$ Reprinted and adapted with permission from E. R. Monazam, R. W. Breault, and R. Siriwardane, Kinetics of hematite to wüstite by hydrogen for chemical looping combustion, Energy Fuels, 2014, 28, 5406-5414, Copyright (2014), American Chemical Society. 
analysed the reduction kinetics of $25 \mathrm{wt} \%$ and $45 \mathrm{wt} \% \mathrm{Fe}_{2} \mathrm{O}_{3}$ on $\mathrm{Al}_{2} \mathrm{O}_{3}$ with a low concentrated $\mathrm{CH}_{4}$ feed of $0.5 \%$. The reduction step of $\mathrm{Fe}_{2} \mathrm{O}_{3} \rightarrow \mathrm{Fe}_{3} \mathrm{O}_{4}$, with a phase change of rhombohedral to cubic, was described with the $2 \mathrm{D}$ growth of nuclei up to solid conversions of 0.7 . At a higher solid conversion, a 3D nuclei growth Avrami Erofeev mechanism yielded better fitting results. The reduction for magnetite to $\mathrm{FeAl}_{2} \mathrm{O}_{4}$ was significantly slower and described by a diffusion-controlled reaction mechanism. The 3D diffusion Jander reaction mechanism fitted best and indicated a strong correlation between the iron content of the sample and the reduction reactivity. Ksepko et al. ${ }^{\mathbf{1 4 4}}$ compared the reduction of $\mathrm{Fe}_{2} \mathrm{O}_{3}$ supported on $20 \mathrm{wt} \% \mathrm{TiO}_{2}$ with a bimetallic sample of $\mathrm{Fe}_{2} \mathrm{O}_{3} / \mathrm{CuO}$ supported on $\mathrm{Al}_{2} \mathrm{O}_{3}(60 / 20 / 20 \mathrm{wt} \%)$ with hydrogen in the temperature range of $600-950{ }^{\circ} \mathrm{C}$. The reaction model of a first order reaction and a phase boundary controlled mechanism was found to be suitable for the $\mathrm{Fe}_{2} \mathrm{O}_{3}$ sample, whereas the 3D diffusion Jander equation and the first order reaction yielded better results for the reduction of the bimetallic oxygen carrier. Jeong et al. ${ }^{\mathbf{1 4 5}}$ investigated the redox kinetics of iron oxides with three different main iron phases $\mathrm{FeOOH}, \mathrm{Fe}_{2} \mathrm{O}_{3}$ and $\mathrm{Fe}_{3} \mathrm{O}_{4}$ with initial surface area of 93.5, 7.5 and $1.7 \mathrm{~m}^{2} \mathrm{~g}^{-1}$. Hence, the transformation to bulk $\mathrm{Fe}_{3} \mathrm{O}_{4}$ with a homogenizing of the different grain sizes was observed. The Jander equation was used to determine the kinetic parameter of the redox reaction. It was suggested that the reduction and oxidation of magnetite led to the highest reaction rate and lowest activation energy. Liu et al. ${ }^{\mathbf{1 4 6}}$ investigated the reduction kinetic of wustite particles in a fluidized bed using $\mathrm{H}_{2}$ and CO. The solid reduction and the formation of metallic iron were divided into three separated conversion stages. The first stage with a solid conversion of $0<X<0.05$ was identified as the partial depletion of oxygen in wustite. In the second stage $0.05<$ $X<0.2$ surface nucleation and the formation of isolated Fe grains took place. The reaction mechanism was controlled by dissociative adsorption and described by a linear reaction model. The final stage $0.2<X<1$ was identified as the thickening of the iron particle with a final formation of a uniform Fe product layer and the changing of the reaction rate to a diffusion limiting system. The random pore model was able to describe the solid conversion reactions. The three stages were also measured when mixtures of $\mathrm{H}_{2}$ and $\mathrm{CO}$ were applied resulting in a superposition of their non-interacting reduction rates. The hydrogen reduction rate was significantly faster than the $\mathrm{CO}$ reduction rate but the overall reduction rate was dominated by the slow diffusion of oxygen atoms in the solid particle.

Plou et al. ${ }^{147}$ incorporated the influence of thermodynamic equilibriums into differential kinetic measurements to reduce deviations during the initial steam oxidation phase and the transition phases. The Johnson-Mehl-Avrami-Kolmogorov model, which provided the differential kinetic data was amalgamated into an integral data fit method based on the Levenberg-Marquardt method by minimizing the sum of square deviation. The simulations were able to take the equilibrium compositions and the moving reaction fronts in the fixed bed reactor into account and yielded improved fitting results. The calculations suggested a decrease of the oxidation activity after consecutive cycles, meaning that the oxidation reaction was primarily responsible for the degradation of the oxygen carrier. Stehle et al. ${ }^{\mathbf{1 4 8}}$ performed steam oxidation experiments with a pristine iron rod. At low steam concentrations in the oxidizing feed, a linear correlation with the produced hydrogen was observed, however higher steam concentrations did not further improve the hydrogen production rate. A rapid increase in the production rate in the range of 1075-1175 K was found, which suggested a transition from the kinetical limited reaction to a diffusion-limited regime. A detailed investigation of the iron oxide layer after the oxidation indicated an average layer thickness of $5 \mu \mathrm{m}$, which deviated significantly in its width after consecutive cycles. ${ }^{149}$ The oxide layer possessed a stoichiometric ratio of $\mathrm{Fe}_{3} \mathrm{O}_{4}$ at the outermost point. A linear decrease to an $\mathrm{O} /$ Fe ratio of 0.8 within $80 \%$ of the layer width was detected, followed by a sharp bend to zero. $70 \%$ of the surface thickness was able to participate in the oxygen exchange reaction with a continuous gradient of oxygen atom concentration, which explained the dominant diffusion limitation. The oxidation of an iron powder with steam in a fluidized bed environment by Singh et al. ${ }^{150}$ showed two bends representing the transition of $\mathrm{Fe} / \mathrm{FeO}$ and $\mathrm{FeO} / \mathrm{Fe}_{3} \mathrm{O}_{4}$. The experimental validation results revealed some deviations from the thermodynamic simulations due to non-ideal mixing of the bed material. At a reaction temperature of $660{ }^{\circ} \mathrm{C}$ the influence of kinetic hindrance was clearly visible resulting in a low conversion. A temperature increase to $960{ }^{\circ} \mathrm{C}$ diminished the kinetic effects.

\section{Conclusions}

Hydrogen production by chemical looping is a very promising technology, where significant scientific progress has been made over the last years. In the area of oxygen carrier development, the focus was on iron as the active component. New synthesis methods and material composition have shown that mixtures with high melting support materials or the incorporation of iron into thermally stable structures, such as perovskites, can successfully enable long-term cycle stability and a satisfying material strength. The addition of different metal oxides, which act as promoters, enhanced the redox properties and permitted the fabrication of specialized and selective oxygen carrier design for specific process conditions and feed stocks. Two- and three reactor moving bed systems in a power range up to $50 \mathrm{~kW}$ have been successfully operated. The experiments revealed stable conditions, a high fuel conversion and a continuous production of hydrogen with high purities. Although, some reactor and system developments using fixed bed technology were presented, most research was related to interconnected fluidized beds. Emphasis has been put on the modification of the chemical looping hydrogen process utilizing different feedstocks. Experimental studies and simulations have shown that the process can handle a variety of renewable resources, different fossil fuels and unconventional materials. The operation parameters were optimized to maximize the hydrogen yield. Energy and exergy analyses showed high efficiencies and excellent capabilities for carbon capturing and thus proved the competitiveness of these systems compared to well-established technologies. However, despite the calculated high system 
efficiencies in system simulations, the chemical looping hydrogen technology still requires prototype plants to be tested in large scale applications in long term operation, which would then demonstrate the advantages under real application scenarios. Furthermore, the oxygen carriers, which indicated satisfying performance in the lab environment, still need to demonstrate their applicability under authentic conditions.

\section{Acknowledgements}

This work is funded by the IEA Research Cooperation on behalf of the Austrian Federal Ministry of Transport, Innovation and Technology.

\section{References}

1 P. Nejat, F. Jomehzadeh, M. Mahdi and M. Gohari, Renewable Sustainable Energy Rev., 2015, 43, 843-862.

2 J. Cook, D. Nuccitelli, S. A. Green, M. Richardson, B. Winkler, R. Painting, R. Way, P. Jacobs and A. Skuce, Environ. Res. Lett., 2013, 8, 1-7.

3 R. K. Pachauri and L. A. Meyer, Climate Change Synthesis Report, IPCC, 2014, p. 151.

4 Adoption of the Paris Agreement Proposal by the President, https://unfccc.int/resource/docs/2015/cop21/eng/ 109r01.pdf, accessed August 2016.

5 J. D. Holladay, J. Hu, D. L. King and Y. Wang, Catal. Today, 2009, 139, 244-260.

6 S. K. Ngoh and D. Njomo, Renewable Sustainable Energy Rev., 2012, 16, 6782-6792.

7 J. Adanez, A. Abad, F. Garcia-Labiano, P. Gayan and L. F. De Diego, Prog. Energy Combust. Sci., 2012, 38, 215-282.

8 R. Chaubey, S. Sahu, O. O. James and S. Maity, Renewable Sustainable Energy Rev., 2013, 23, 443-462.

9 H. H. Gastineau and H. Lane, GB pat., 190310356, 2014.

10 H. Lane, US pat., 1028366, 1912.

11 H. Lane, US pat., 1078686, 1913.

12 A. Messerschmitt, US pat., 971206, 1910.

13 F. Bergius, US pat., 1059818, 1913.

14 C. E. Parsons, US pat., 1658939, 1926.

15 W. H. Marshall, US pat., 2182747, 1939.

16 L. Fan, Chemical Looping Systems for Fossil Energy Conversions, John Wiley \& Sons, Inc., Hoboken, New Jersey, 2010.

17 A. Thursfield, A. Murugan, R. Franca and I. S. Metcalfe, Energy Environ. Sci., 2012, 5, 7421-7459.

18 V. Hacker, J. Power Sources, 2003, 118, 311-314.

19 S. D. Fraser, M. Monsberger and V. Hacker, J. Power Sources, 2006, 161, 420-431.

20 D. D. Miller and R. Siriwardane, Energy Fuels, 2013, 27, 4087-4096.

21 B. Dou, Y. Song, C. Wang, H. Chen and Y. Xu, Renewable Sustainable Energy Rev., 2013, 30, 950-960.

22 E. Lorente, J. A. Peña and J. Herguido, Int. J. Hydrogen Energy, 2008, 33, 615-626.

23 F. Li, H. R. Kim, D. Sridhar, F. Wang, L. Zeng, J. Chen and L.-S. Fan, Energy Fuels, 2009, 23, 4182-4189.
24 M. Ortiz, L. F. De Diego, A. Abad, F. García-Labiano, P. Gayan and J. Adanez, Energy Fuels, 2012, 26, 791-800.

25 X.-L. Liu, X.-J. Yin and H. Zhang, Energy Fuels, 2014, 28, 6066-6076.

26 R. D. Solunke, Ind. Eng. Chem. Res., 2010, 49, 11037-11044.

27 P. Gupta, L. G. Velazquez-vargas and L. Fan, Energy Fuels, 2007, 21, 2900-2908.

28 M. Thaler, V. Hacker, M. Anilkumar, J. Albering, J. O. Besenhard, H. Schröttner and M. Schmied, Int. J. Hydrogen Energy, 2006, 31, 2025-2031.

29 V. J. Aston, B. W. Evanko and A. W. Weimer, Int. J. Hydrogen Energy, 2013, 38, 9085-9086.

30 W. C. Cho, D. Y. Lee, M. W. Seo, S. D. Kim, K. S. Kang, K. K. Bae, C. H. Kim, S. U. K. Jeong and C. S. Park, Appl. Energy, 2014, 113, 1667-1674.

31 X. Zhu, Y. Wei, H. Wang and K. Li, Int. J. Hydrogen Energy, 2013, 38, 4492-4501.

32 H. Fang, L. Haibin and Z. Zengli, Int. J. Chem. Eng., 2009, 116.

33 N. L. Galinsky, Y. Huang and F. Li, Sustainable Chem. Eng., 2013, 1, 364-373.

34 W. Liu, J. S. Dennis and S. A. Scott, Ind. Eng. Chem. Res., 2012, 51, 16597-16609.

35 W. C. Cho, C. G. Kim, S. U. Jeong, C. S. Park, K. S. Kang, D. Y. Lee and S. D. Kim, Ind. Eng. Chem. Res., 2015, 54, 3091-3100.

36 W. C. Cho, M. W. Seo, S. D. Kim, K. S. Kang, K. K. Bae, H. Kim, S. U. Jeong and C. S. Park, Int. J. Hydrogen Energy, 2012, 37, 16852-16863.

37 F. Kosaka, H. Hatano, Y. Oshima and J. Otomo, Chem. Eng. Sci., 2015, 123, 380-387.

38 Y. Zheng, X. Zhu, H. Wang, K. Li, Y. Wang and Y. Wei, J. Rare Earths, 2014, 32, 842-848.

39 Y. Zheng, Y. Wei, K. Li, X. Zhu, H. Wang and Y. Wang, Int. J. Hydrogen Energy, 2014, 39, 13361-13368.

40 X. Zhu, K. Li, Y. Wei, H. Wang and L. Sun, Energy Fuels, 2014, 28, 754-760.

41 Z. Gu, K. Li, S. Qing, X. Zhu, Y. Wei, Y. Li and H. Wang, RSC Adv., 2014, 4, 47191-47199.

42 E. Romero, R. Soto, P. Durán, J. Herguido and J. A. Peña, Int. J. Hydrogen Energy, 2011, 37, 6978-6984.

43 P. Datta, L. K. Rihko-Struckmann and K. Sundmacher, Mater. Chem. Phys., 2011, 129, 1089-1095.

44 P. Datta, L. K. Rihko-Struckmann and K. Sundmacher, Fuel Process. Technol., 2014, 128, 36-42.

45 H. Wang, J. Zhang, F. Wen and J. Bai, RSC Adv., 2013, 3, 10341-10348.

46 P. Datta, Mater. Res. Bull., 2013, 48, 4008-4015.

47 M. Ismail, W. Liu, M. T. Dunstan and S. A. Scott, Int. J. Hydrogen Energy, 2015, 41, 4073-4084.

48 M. S. C. Chan, W. Liu, M. Ismail, Y. Yang, S. A. Scott and J. S. Dennis, Chem. Eng. J., 2016, 296, 406-411.

49 P. R. Kidambi, J. P. E. Cleeton, S. A. Scott, J. S. Dennis and C. D. Bohn, Energy Fuels, 2012, 26, 603-617.

50 A. M. Kierzkowska, C. D. Bohn, S. A. Scott, J. P. Cleeton, J. S. Dennis and C. R. Müller, Ind. Eng. Chem. Res., 2010, 49, 5383-5391. 
51 C. D. Bohn, J. P. Cleeton, C. R. Müller, S. A. Scott and J. S. Dennis, Energy Fuels, 2010, 24, 4025-4033.

52 M. Ishida, K. Takeshita, K. Suzuki and T. Ohba, Energy Fuels, 2005, 19, 2514-2518.

53 W. Liu, M. Ismail, M. T. Dunstan, W. Hu, Z. Zhang, P. S. Fennell, S. A. Scott and J. S. Dennis, RSC Adv., 2015, 5, 1759-1771.

54 M. Mufti, E. Jerndal, H. Leion, T. Mattisson and A. Lyngfelt, Chem. Eng. Res. Des., 2010, 88, 1505-1514.

55 F. Liu, Y. Zhang, L. Chen, D. Qian, J. K. Neathery, S. Kozo and K. Liu, Energy Fuels, 2013, 27, 5987-5995.

56 H. Leion, A. Lyngfelt, M. Johansson, E. Jerndal and T. Mattisson, Chem. Eng. Res. Des., 2008, 86, 1017-1026.

57 Y. Ku, Y.-C. Liu, P.-C. Chiu, Y.-L. Kuo and Y.-H. Tseng, Ceram. Int., 2014, 40, 4599-4605.

58 R. Xiao, S. Zhang, S. Peng, D. Shen and K. Liu, Int. J. Hydrogen Energy, 2014, 39, 19955-19969.

59 A. Tong, S. Bayham, M. V. Kathe, L. Zeng, S. Luo, L.-S. Fan and W. G. Lowrie, Appl. Energy, 2014, 113, 1836-1845.

60 W. Liu, L. Shen, H. Gu and L. Wu, Energy Fuels, 2016, 30, 1756-1763.

61 F.-X. Chiron and G. S. Patience, Int. J. Hydrogen Energy, 2012, 37, 10526-10538.

62 T. D. L. R. Castillo, L. C. Palacios, S. A. D. L. Ríos, D. D. Vigil, J. S. Gutiérrez, A. L. Ortiz and V. Collins-Martínez, J. New Mater. Electrochem. Syst., 2012, 12, 55-61.

63 T. D. L. R. Castillo, J. S. Gutiérrez, A. L. Ortiz and V. CollinsMartínez, Int. J. Hydrogen Energy, 2013, 38, 12519-12526.

64 H. Liang, Int. J. Hydrogen Energy, 2015, 40, 13338-13343.

65 N. L. Galinsky, A. Shafiefarhood, Y. Chen, L. Neal and F. Li, Appl. Catal., B, 2015, 164, 371-379.

66 K. Zhao, F. He, Z. Huang, A. Zheng, H. Li and Z. Zhao, Int. J. Hydrogen Energy, 2014, 39, 3243-3252.

67 K. Zhao, F. He, Z. Huang, G. Wei, A. Zheng, H. Li and Z. Zhao, Appl. Energy, 2016, 168, 193-203.

68 I. Popescu, Y. Wu, P. Granger and I. Marcu, Appl. Catal., A, 2014, 485, 20-27.

69 C. Feng, S. Ruan, J. Li, B. Zou, J. Luo, W. Chen, W. Dong and F. Wu, Sens. Actuators, B, 2011, 155, 232-238.

70 W. Haron, T. Thaweechai and W. Wattanathana, Energy Procedia, 2013, 34, 791-800.

71 F. He and F. Li, Energy Environ. Sci., 2015, 8, 535-539.

72 T. A. S. Ferreira, J. C. Waerenborgh, M. H. R. M. Mendonça, M. R. Nunes and F. M. Costa, Solid State Sci., 2003, 5, 383392.

73 D. S. Mathew and R. Juang, Chem. Eng. J., 2007, 129, 51-65.

74 E. Manova, B. Kunev, D. Paneva, I. Mitov and L. Petrov, Chem. Mater., 2004, 16, 5689-5696.

75 Y. Qu, H. Yang, N. Yang, Y. Fan, H. Zhu and G. Zou, Mater. Lett., 2006, 60, 3548-3552.

76 K. Svoboda, G. Slowinski, J. Rogut and D. Baxter, Energy Convers. Manage., 2007, 48, 3063-3073.

77 V. Crocellà, F. Cavani, G. Cerrato, S. Cocchi, M. Comito, G. Magnacca and C. Morterra, J. Phys. Chem. C, 2012, 116, 14998-15009.

78 S. Cocchi, M. Mari, F. Cavani and J.-M. M. Millet, Appl. Catal., B, 2014, 152-153, 250-261.
79 C. Trevisanut, M. Mari, J.-M. M. Millet and F. Cavani, Int. J. Hydrogen Energy, 2015, 40, 5264-5271.

80 O. Vozniuk, S. Agnoli, L. Artiglia, A. Vassoi, N. Tanchoux, F. Di Renzo, G. Granozzi and F. Cavani, Green Chem., 2016, 18, 1038-1050.

81 Y. Kuo, W. Huang, W. Hsu, Y. Tseng and Y. Ku, Aerosol Air Qual. Res., 2015, 15, 2700-2708.

82 S. Bhavsar, M. Najera, R. Solunke and G. Veser, Catal. Today, 2014, 228, 96-105.

83 A. Edrisi, Z. Mansoori and B. Dabir, Int. J. Hydrogen Energy, 2014, 39, 8271-8282.

84 M. Rydén and M. Arjmand, Int. J. Hydrogen Energy, 2012, 37, 4843-4854.

85 D. Sanfilippo, Catal. Today, 2016, 272, 58-68.

86 M. Sorgenfrei and G. Tsatsaronis, Appl. Energy, 2014, 113, 1958-1964.

87 D. Zeng, R. Xiao, Z. Huang, J. Zeng and H. Zhang, Int. J. Hydrogen Energy, 2016, 41, 6676-6684.

88 Z. Xue, S. Chen, D. Wang and W. Xiang, Ind. Eng. Chem. Res., 2012, 51, 4267-4278.

89 J. Herguido, J. Peña and E. Carazo, Int. J. Hydrogen Energy, 2014, 39, 14050-14060.

90 S. Chen, Z. Xue, D. Wang and W. Xiang, Int. J. Hydrogen Energy, 2012, 37, 8204-8216.

91 D. Sridhar, A. Tong, H. Kim, L. Zeng, F. Li, L.-S. Fan and W. G. Lowrie, Energy Fuels, 2012, 26, 2292-2302.

92 A. Tong, D. Sridhar, Z. Sun, H. R. Kim, L. Zeng, F. Wang, D. Wang, M. V. Kathe, S. Luo, Y. Sun and L. S. Fan, Fuel, 2013, 103, 495-505.

93 A. Tong, L. Zeng, M. V Kathe, D. Sridhar, L.-S. Fan and W. G. Lowrie, Energy Fuels, 2013, 27, 4119-4128.

94 M. V. Kathe, A. Empfield, J. Na, E. Blair and L. Fan, Appl. Energy, 2016, 165, 183-201.

95 B. Moghtaderi, Chem. Eng. Res. Des., 2012, 90, 19-25.

96 B. Moghtaderi and E. Doroodchi, Int. J. Hydrogen Energy, 2012, 37, 15164-15169.

97 D.-W. Zeng, R. Xiao, S. Zhang and H.-Y. Zhang, Fuel Process. Technol., 2015, 139, 1-7.

98 W. C. Cho, D. Y. Lee, M. W. Seo, S. D. Kim, K. Kang, K. K. Bae, H. Kim, S. Jeong and C. S. Park, Appl. Energy, 2014, 113, 1667-1674.

99 Y. S. Hong, K. S. Kang, C. S. Park, D. Kim, J. W. Bae, J. W. Nam, Y. Lee and D. H. Lee, Int. J. Hydrogen Energy, 2013, 38, 6052-6058.

100 D. Lee, M. W. Seo, T. D. B. Nguyen, W. C. Cho and S. D. Kim, Int. J. Hydrogen Energy, 2014, 39, 14546-14556.

101 E. Hormilleja, P. Durán, J. Plou, J. Herguido and J. A. Peña, Int. J. Hydrogen Energy, 2014, 39, 5267-5273.

102 R. Campo, P. Durán, J. Plou, J. Herguido and J. A. Peña, J. Power Sources, 2013, 242, 520-526.

103 C. Trevisanut, F. Bosselet, F. Cavani and J. M. M. Millet, Catal.: Sci. Technol., 2015, 3, 1280-1289.

104 M. G. Rosmaninho, F. C. C. Moura, L. R. Souza, R. K. Nogueira, G. M. Gomes, J. S. Nascimento, M. C. Pereira, J. D. Fabris, J. D. Ardisson, M. S. Nazzarro, K. Sapag, M. H. Araújo and R. M. Lago, Appl. Catal., B, 2012, 115-116, 45-52. 
105 J. Plou, P. Durán, J. Herguido and J. A. Peña, Fuel, 2014, 118, 100-106.

106 J. Plou, P. Durán, J. Herguido and J. A. Peña, Fuel, 2015, 140, 470-476.

107 M. Herrer, J. Plou, P. Durán, J. Herguido and J. A. Peña, Int. J. Hydrogen Energy, 2015, 40, 5244-5250.

108 G. Voitic, S. Nestl, K. Malli, J. Wagner, B. Bitschnau, F. Mautner and V. Hacker, RSC Adv., 2016, 6, 53533-53541.

109 S. Nestl, G. Voitic, M. Lammer, B. Marius, J. Wagner and V. Hacker, J. Power Sources, 2015, 280, 57-65.

110 G. Voitic, S. Nestl, M. Lammer, J. Wagner and V. Hacker, Appl. Energy, 2015, 157, 399-407.

111 Y. Tsai, L. Liu and D. Chen, RSC Adv., 2016, 6, 8930-8934.

112 K. Michiels, J. Spooren and V. Meynen, Fuel, 2015, 160, 205216.

113 A.-M. Cormos and C.-C. Cormos, Int. J. Hydrogen Energy, 2014, 39, 2067-2077.

114 C. Cormos, A. Cormos and L. Petrescu, Chemical Engineering Transactions, 2014, 39, 247-252.

115 C.-C. Cormos, Int. J. Greenhouse Gas Control, 2012, 37, 13371-13386.

116 C.-C. Cormos, A.-M. Cormos and L. Petrescu, Chem. Eng. Res. Des., 2014, 92, 741-751.

117 S. Mukherjee, P. Kumar, A. Hosseini, A. Yang and P. Fennell, Energy Fuels, 2014, 28, 1028-1040.

118 Q. Yang, Y. Qian, Y. Wang, H. Zhou and S. Yang, Ind. Eng. Chem. Res., 2015, 54, 6156-6164.

119 L. Zeng, F. He, F. Li, L.-S. Fan and W. G. Lowrie, Energy Fuels, 2012, 26, 3680-3690.

120 S. Chen, Z. Xue, D. Wang and W. Xiang, J. Power Sources, 2012, 215, 89-98.

121 H. Ozcan and I. Dincer, Energy Convers. Manage., 2014, 85, 477-487.

122 K.-S. Kang, C.-H. Kim, K.-K. Bae, W.-C. Cho, S.-U. Jeong, S.-H. Kim and C.-S. Park, Int. J. Hydrogen Energy, 2012, 37, 3251-3260.

123 M. N. Khan and T. Shamim, Appl. Energy, 2016, 162, 11861194.

124 X. Zhang, S. Li, H. Hong and H. Jin, Energy Convers. Manage., 2014, 85, 701-708.

$125 \mathrm{X}$. Zhang and H. Jin, Appl. Energy, 2013, 112, 800-805.

126 X. Zhang, S. Li and H. Jin, Energies, 2014, 7, 7166-7177.

127 C.-C. Cormos, Fuel Process. Technol., 2015, 137, 16-23.

128 L. Yan, G. Yue and B. He, Bioresour. Technol., 2016, 205, 133-141.
129 L. Yan, B. He, X. Pei, C. Wang, Z. Duan, J. Song and X. Li, Int. J. Hydrogen Energy, 2014, 39, 17540-17553.

130 C.-C. Cormos, Int. J. Hydrogen Energy, 2014, 39, 5597-5606.

131 S. G. Gopaul, A. Dutta and R. Clemmer, Int. J. Hydrogen Energy, 2014, 39, 5804-5817.

132 A. Sanz, D. Nieva and J. Dufour, Int. J. Hydrogen Energy, 2015, 40, 5074-5080.

133 A. Edrisi, Z. Mansoori, B. Dabir and A. Shahnazari, Int. J. Hydrogen Energy, 2014, 39, 10380-10391.

134 J. Zhu, W. Wang, X. N. Hua, F. Wang, Z. Xia and Z. Deng, Int. J. Hydrogen Energy, 2015, 40, 12097-12107.

135 X. Hua, W. Wang and Y. Hu, J. Mater. Cycles Waste Manage., 2014, 16, 583-590.

136 X. Hua, W. Wang and F. Wang, Front. Environ. Sci. Eng., 2015, 9, 1130-1138.

137 C. Hertel, P. Heidebrecht and K. Sundmacher, Int. J. Hydrogen Energy, 2012, 37, 2195-2203.

138 K.-S. Kang, C.-H. Kim, K.-K. Bae, W.-C. Cho, S.-U. Jeong, Y.-J. Lee and C.-S. Park, Chem. Eng. Res. Des., 2014, 92, 2584-2597.

139 S. Nasr and K. P. Plucknett, Energy Fuels, 2014, 28, 13871395.

140 E. R. Monazam, R. W. Breault and R. Siriwardane, Energy Fuels, 2014, 28, 5406-5414.

141 E. R. Monazam, R. W. Breault, R. Siriwardane, G. Richards and S. Carpenter, Chem. Eng. J., 2013, 232, 478-487.

142 Y. Zhang, E. Doroodchi and B. Moghtaderi, Energy Fuels, 2015, 29, 337-345.

143 Y. Zhang, E. Doroodchi and B. Moghtaderi, Appl. Energy, 2014, 113, 1916-1923.

144 E. Ksepko, M. Sciazko and P. Babinski, Appl. Energy, 2013, 115, 374-383.

145 M. H. Jeong, D. H. Lee and J. W. Bae, Int. J. Hydrogen Energy, 2015, 40, 2613-2620.

146 W. Liu, J. Y. Lim, M. A. Saucedo, A. N. Hayhurst, S. A. Scott and J. S. Dennis, Chem. Eng. Sci., 2014, 120, 149-166.

147 J. Plou, P. Duran, J. Herguido and J. A. Peña, Int. J. Hydrogen Energy, 2012, 37, 6995-7004.

148 R. C. Stehle, M. M. Bobek and D. W. Hahn, Int. J. Hydrogen Energy, 2015, 40, 1675-1689.

149 M. M. Bobek, R. C. Stehle and D. W. Hahn, Materials, 2012, 5, 2003-2014.

150 A. Singh, F. Al-Raqom, J. Klausner and J. Petrasch, Int. J. Hydrogen Energy, 2012, 37, 7442-7450. 